\title{
Structural and Stratigraphic Modeling Techniques in Shale and Tight Oil Basin Reservoir Studies
}

Robin Dommisse. Bureau of Economic Geology, Jackson School of Geosciences, The University of Texas at Austin

Author email: robin.dommisse@beg.utexas.edu

Twitter: @Dommisse3DGeo

This is a Preprint. Please note that, despite currently undergoing peer-review, the manuscript has yet to be formally accepted for publication. Subsequent versions of this manuscript may have slightly different content. If accepted, the final version of this manuscript will be available via the 'Peer-reviewed Publication DOI' link on the right-hand side of this webpage. Please feel free to contact the author if you would like to provide feedback. 


\section{Structural and Stratigraphic Modeling Techniques in Shale and Tight Oil Basin Reservoir Studies}

Robin Dommisse. Bureau of Economic Geology, Jackson School of Geosciences, The University of Texas at Austin

Author email: robin.dommisse@beg.utexas.edu

\section{Abstract}

The validity of regional and basin-wide geomodels of unconventional and tight-oil plays depends on the accuracy and precision of the available structural and stratigraphic frameworks. Integrated reservoir models, combining seismic, log, core, and production data, are critical tools necessary for capturing the complexity of basin fill history and for understanding the 3D facies architecture. For researchers, a lack of publicly available 3D seismic surveys, even in basins with a high density of wells, is an impediment to creating accurate models of faults and stratigraphic zones. Three approaches were used to overcome this deficit: 1) well log correlation of detailed stratigraphic zones using densely spaced vertical wells; 2 ) calculation of trend surfaces from thousands of geosteered 3D horizontal well position logs; and 3) residual analysis of regional and local horizontal well trend surfaces to identify faults. Independent data was used to confirm the validity of these new surfaces and faults, including 3D seismic interpretations (where available), well log-based fault correlations, and analysis of seismicity. The resulting horizons were used to increase the accuracy and precision of the structure and stratigraphy input for the 3D geocellular models. Examples of the approaches to refining geomodels are illustrated for the main North American unconventional reservoir and tight oil plays, including the Eagle Ford, Bakken, Barnett, Haynesville, Fayetteville, Marcellus, and the Midland and Delaware Basins.

\section{Introduction}

At the end of 2019, the EIA reported shale gas proved reserves of 353.1 trillion cubic feet (Tcf) in the US. At the same time, the proved reserves for the Permian Basin tight oil were reported at 11.1 billion barrels. These reserves contributed to the US being able to achieve the number one worldwide ranking in both natural gas and oil production in 2019. The US currently ranks number four in the world in total natural gas reserves and ranks $10^{\text {th }}$ in the world in total oil and condensate reserves (EIA, 2019).

The continued development of these hydrocarbon resources using hydraulically fractured wells has a large impact on future oil production. Accurate regional interpretations of the subsurface geology can help operators identify future development prospects. These interpretations depend on the availability of horizontal well logs used for geological correlation, and on 3D seismic volumes used for seismic interpretation. However, much of this data is not publicly available.

Researchers who do not have access to 3D seismic volumes needed for seismic horizon interpretation use well log correlation methods instead to define stratigraphic zones in regional geological stratigraphic studies. In many cases, thousands of wells containing logs suitable for stratigraphic well log correlation are available in the public domain. Undersampling the total number of these well log correlation wells available in a shale or tight-oil basin leads to significant inaccuracies in landing zone calculations. Landing zones are defined as hydrocarbon-bearing stratigraphic zones targeted by geosteerers for the positioning of the horizontal leg of a production well. The definition of these stratigraphic zones is the result of geological well log interpretation in vertical wells. Using too few of these vertical correlation wells results in a reduction of 
the structural and stratigraphic accuracy of the interwell horizon surfaces defining the tops and bases of these stratigraphic zones.

The aim of this study was to improve the quality of the stratigraphic and structural frameworks of these major shale gas and tight oil plays. In this study, I constructed integrated 3D geocellular reservoir models (geomodels) of six shale gas basins and two tight oil basins (Figure 1). I used these geomodels to analyze the stratigraphic landing zones of hydraulically fractured wells obtained from publicly available data. I used a trend analysis technique applied to over 75,000 horizontal wells to predict more accurate stratigraphic horizons and to identify faults. This technique was originally developed by Dommisse (2018) for singleformation landing zones in the Haynesville study and subsequently refined for multi-formation landing zones in the Midland Basin and Delaware Basin studies.

This paper presents a method to improve the quality of stratigraphic and structural interpretations and to create more accurate 3D geomodels. These geomodels can then be used to integrate geological and engineering parameters required for the continued development of shale and tight-oil plays.

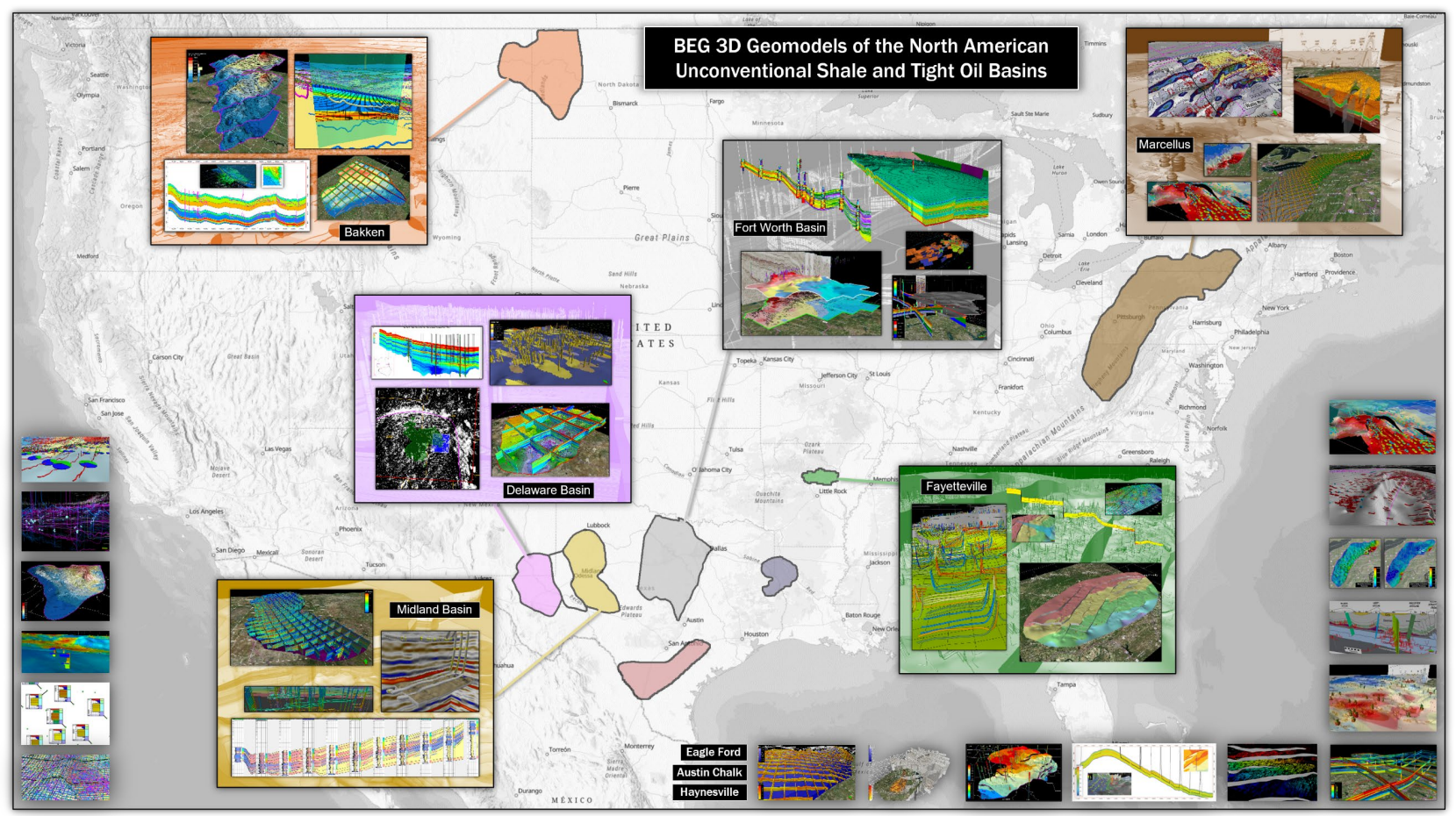

Figure 1 - Integrated 3D geocellular reservoir models of six shale gas basins including the Eagle Ford, Bakken, Barnett, Fayetteville, Haynesville, Marcellus, and two tight oil basins including the Midland Basin and Delaware Basin.

\section{Methods}

\subsection{Datasets}

This work utilizes data for horizontal and vertical well trajectories and well log formation tops obtained from IHS Marklt using the Enerdeq Browser.

\begin{tabular}{|l|l|l|l|}
\hline Study & $\begin{array}{l}\text { Number of correlation } \\
\text { wells }\end{array}$ & $\begin{array}{l}\text { Number of well log } \\
\text { formation tops } \\
\text { interpreted for } \\
\text { landing zone targets }\end{array}$ & $\begin{array}{l}\text { Number of horizontal } \\
\text { wells }\end{array}$ \\
\hline Eagle Ford & 350 & 3 & 19,000 \\
\hline Bakken & 885 & 8 & 9,800 \\
\hline Barnett & 225 & 5 & 15,000 \\
\hline Fayetteville & 150 & 2 & 5,600 \\
\hline
\end{tabular}




\begin{tabular}{|l|l|l|l|}
\hline Haynesville & 180 & 2 & 3,600 \\
\hline Marcellus & 750 & 2 & 7,000 \\
\hline Midland Basin & 1,500 & 11 & 6,000 \\
\hline Delaware Basin & 1,500 & 11 & 9,000 \\
\hline
\end{tabular}

Table 1 - Correlation well, well log tops, horizontal well datasets

\subsection{Stratigraphic framework interpretation using well log correlation}

The stratigraphic frameworks created in this study are based on well log correlation techniques described in Tearpock \& Bischke (2002), consisting of well log curve pattern correlation between vertical wells. The number of correlation wells used in each of the geomodels used in this study are listed in Table 1.

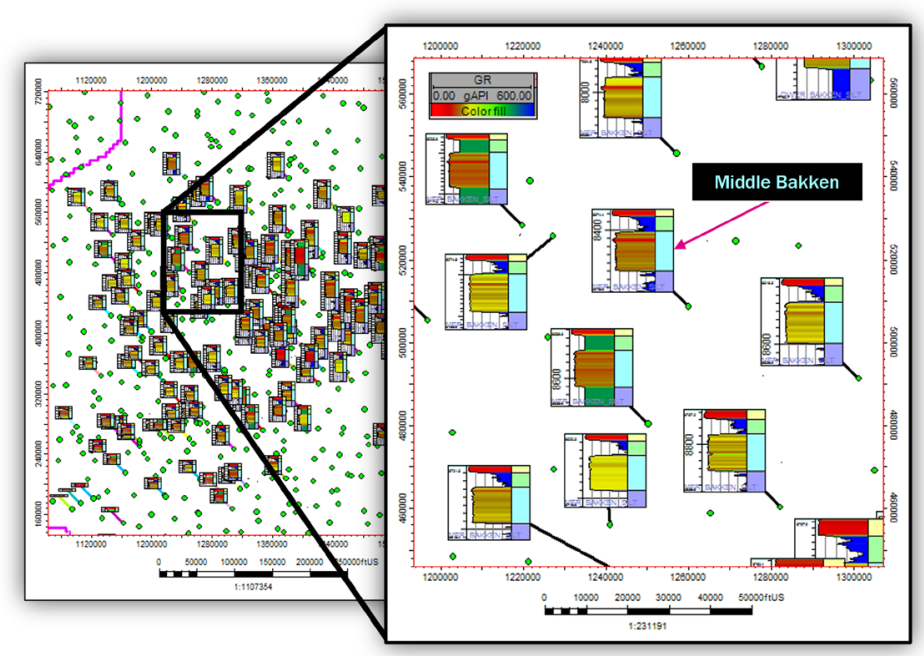

Figure 2 - Log signature map of well log curves in the Bakken study. Gamma ray well log curves are shown increasing from left to right. The middle Bakken formation is shown as a zone with relatively lower gamma ray values.

\subsection{Surface modeling of stratigraphic horizons}

The stratigraphic horizons modeled in this study were generated using the convergent interpolation gridding algorithm of the Schlumberger Petrel software application. This algorithm uses an iterative technique to minimize grid curvature using a constrained, biharmonic operator. The convergent interpolation gridding technique preserves general trends in areas with few well log tops while detail is honored in areas where more tops exist.

\subsection{Creating a horizontal well position log trend surface}

I downloaded horizontal well directional surveys from the IHS Marklt Enerdeq website and imported these files into the Schlumberger Petrel tool using the "Multiple Well Paths/Deviations (ASCII)" import format. A well directional survey typically contains measured depth, inclination (deviation), and azimuth (direction of deviation) information. Next, I used the Petrel software to convert the directional surveys to positions log using a minimum curvature fitting method based on algorithms described in Sawaryn \& Thorogood (2003). The position logs contain the map projection X \& Y locations and the subsea elevation $Z$ values. Next, I exported these position logs to individual ASCII text files. These files were subsequently merged into a single $X Y Z$ pointset file. Each of the $X Y Z$ records is preceded with a 14-digit API unique well identifier. The XYZ pointset records also contain point-to-point wellbore inclination and dogleg severity (DLS) data which is a measure of the change in inclination or direction of a borehole.

Next, I imported the XYZ pointset file containing the well position logs into Petrel using the "Petrel points with attributes (ASCII)" import format. The pointset was filtered to exclude points with inclination values greater than 80 degrees. This pointset was then converted to a surface using the convergent interpolation gridding algorithm. The resulting surface represents the horizontal well position log trend surface (Figure 3). 


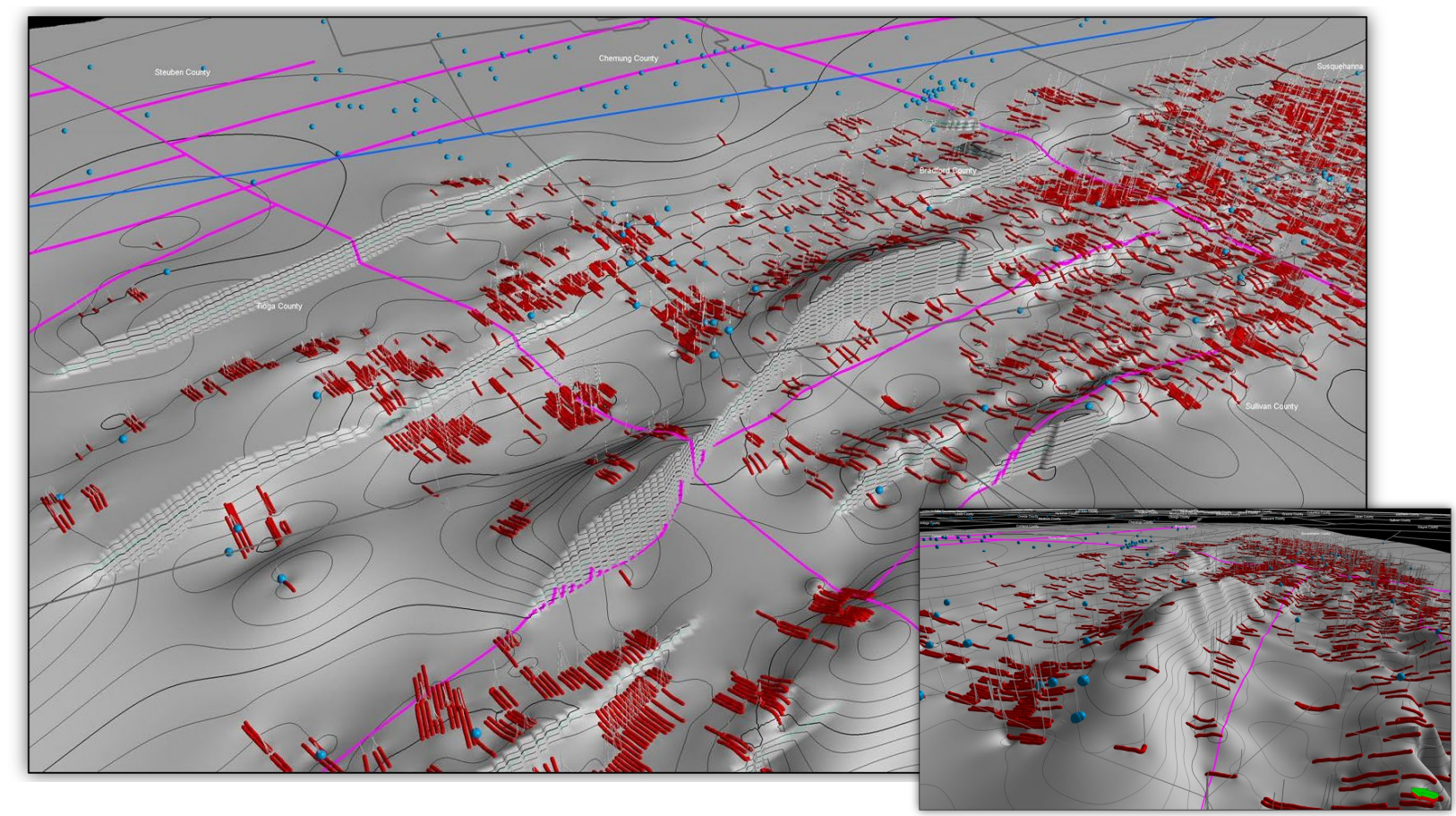

Figure 3 - Horizontal well position log trend surface. Horizontal well position logs are shown in red. The inset image shows the surface generated from the position logs prior to applying fault traces in the surface modeling algorithm. The main image shows the faulted horizontal well position log trend surface. Vertical exaggeration is $10 x$.

\subsection{Trend analysis of horizontal well position log dataset}

Horizon dip angle is defined as the maximum dip angle of a 3D horizon interpretation, measured from a horizontal plane $\left(0\right.$ to $\left.90^{\circ}\right)$. The dip azimuth represents the azimuth of the maximum dip angle, measured in degrees from north $\left(0\right.$ to $\left.360^{\circ}\right)$ of the $3 \mathrm{D}$ horizon interpretation. I calculated both parameters at each of the grid nodes of the well position log trend surface. Figure 4 shows the dip angle magnitude for this surface, highlighting areas where the well position log trend surface experiences high dips due to its honoring the well trajectory data points of closely spaced, vertically stacked horizontal producers.

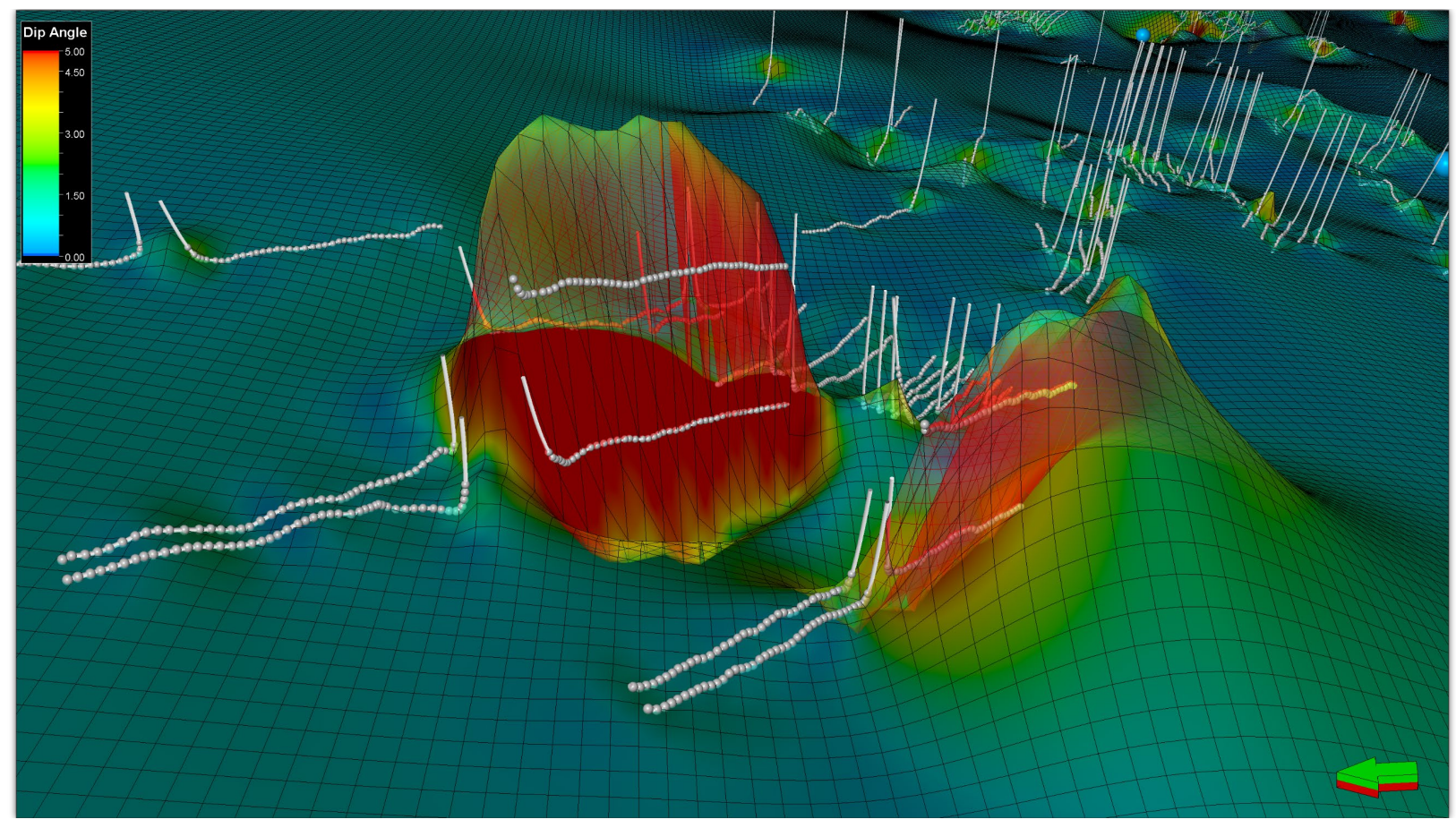

Figure 4 - Dip-angle attribute display for well position log trend surface for horizontal producers in the Marcellus Shale. Vertical exaggeration is $10 x$. 
In shale and tight oil reservoirs that mainly target a single zone, the next step was to apply a smoothing algorithm to the areas of the well position log trend surface with high dip values to establish the main trend horizon to be used for outlier-identification residual calculations, as described in the next section.

\subsection{Classifying and correcting landing zones for position logs}

To calculate and assign the landing zones for the horizontal wells, I used an algorithm that takes the elevation value of each of the well position log points and compares it to a back-interpolated value of the elevation of a surface at the matching $X$ and $Y$ location. The left image in Figure 5 shows the distances from different points in the wellbore to the top of the Haynesville formation. I used the same vertical distance calculation to assign distances to the previously calculated position log trend surface, shown in the right image in Figure 5. Blue and red well trajectory points all fall outside of a 100-foot interval centered on the trend surface and were classified as outlier wells that need to be investigated. In many cases, these outlier wells target a different producing formation or reveal data management problems, such as incorrect well datum elevations (e.g. Kelly-bushing values).
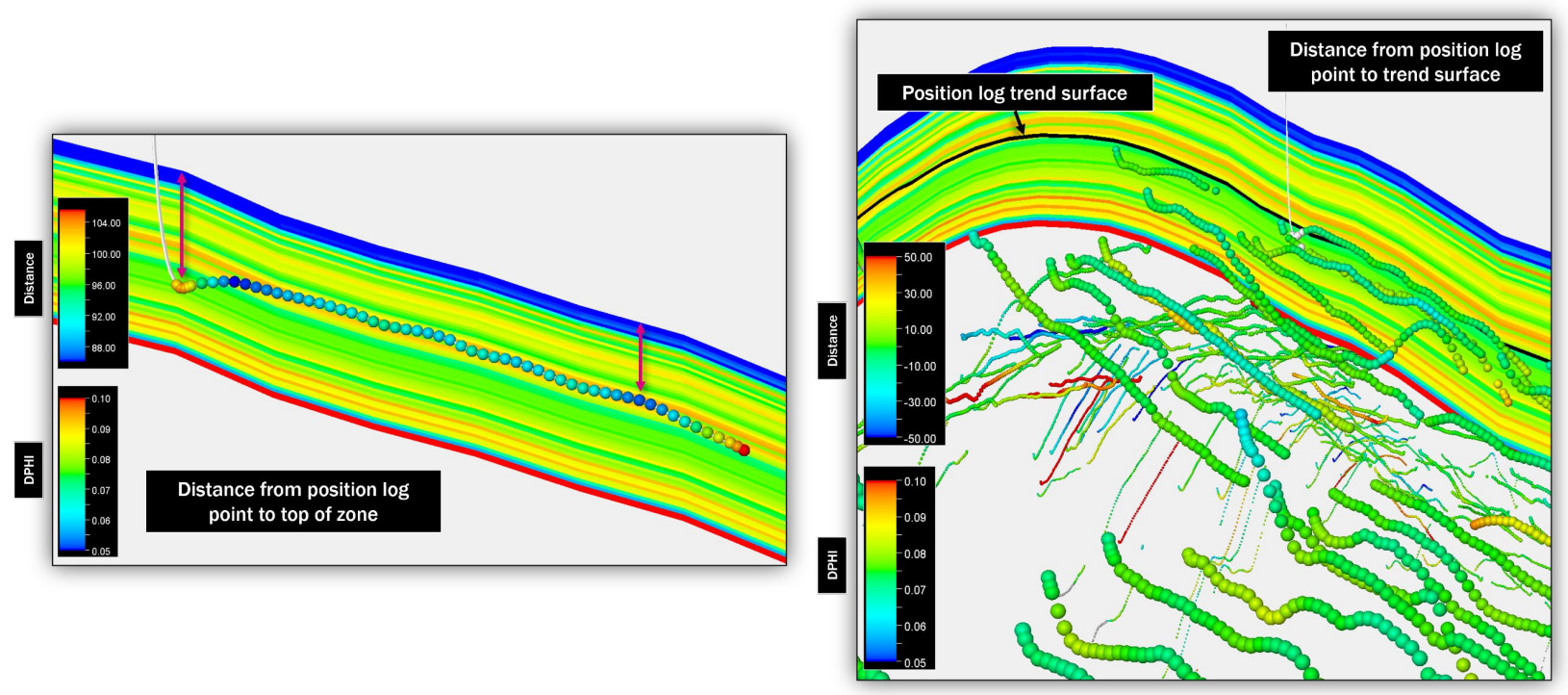

Figure 5 - In the left image is a Haynesville horizontal well with position log points colored by vertical distance to of top of the Haynesville stratigraphic zone. The right image shows the distance of the horizontal well position log points to the position log trend surface based on all of the points in the Haynesville project area. The color of the cross-sections represents density-porosity. Vertical exaggeration is $10 x$.

Modern geomodeling software applications often include the ability to efficiently edit pointsets visualized in three dimensions using pointset manipulation, including selection and erasure tools. Figure 6 describes the process of manually correcting well trajectory data points that fall outside of the vertical depthrange tolerance of the current well position log trend surface. In this workflow I identified the outlier wells using the dip attributes and distance to position log trend surfaces workflows described in the previous sections. In Figure $6 a$ is an outlier well with an incorrect landing zone assignment of the Haynesville shale, when in fact this well should have been classified as a Bossier horizontal producer. Selecting these well position log points using the 3D pointset editing tool and removing them results in the correction of the position log trend surface for the Haynesville shale landing zone. 


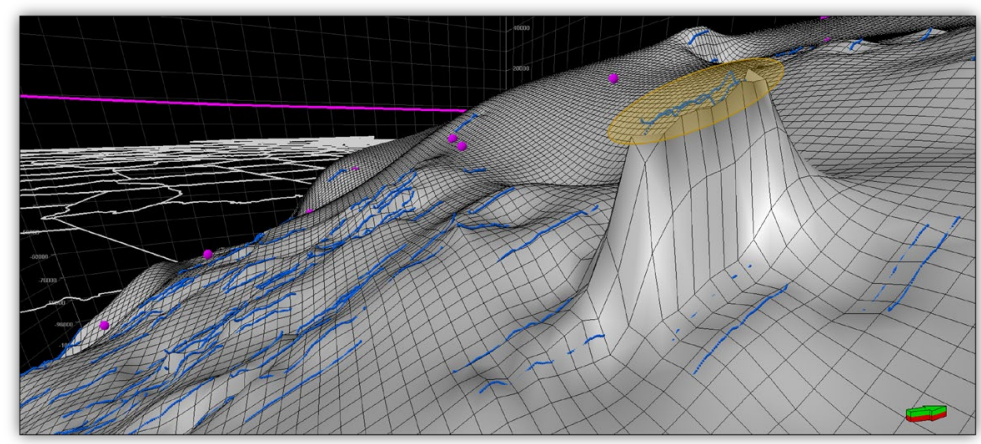

a) Haynesville well position log trend surface showing a well that is misclassified as having been completed in the Haynesville shale.

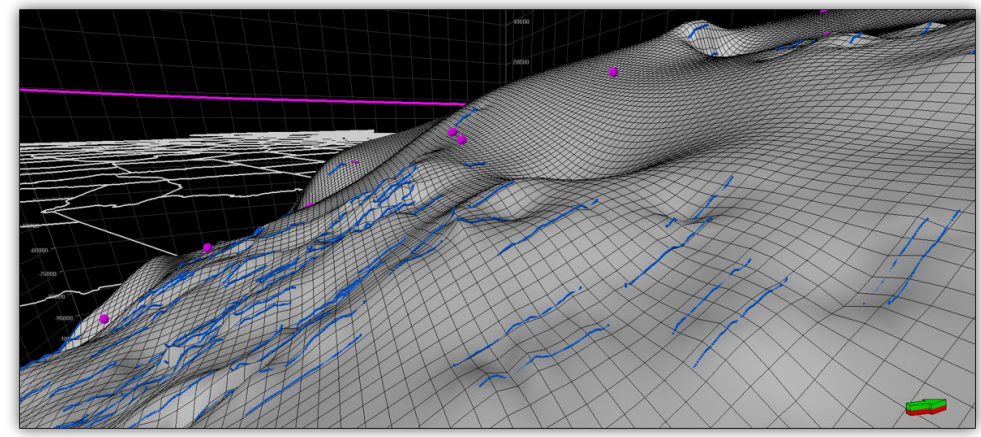

b) Corrected well position log trend surface.

Figure 6 -Correction of position log pointsets with incorrect landing zone classifications. Vertical exaggeration is 10x.

\subsection{Fault identification using horizontal well position log trend surfaces}

Figure 7 shows a combination of map, cross-section, and 3D views used to identify faults highlighted by the well position log trend surface. The mapview shows the elevation colors of each of the well trajectory survey points superimposed on the elevation colors of the trend surface. Analysis of the elevation trends enables the identification of two distinct faults in this area of the Haynesville shale play.
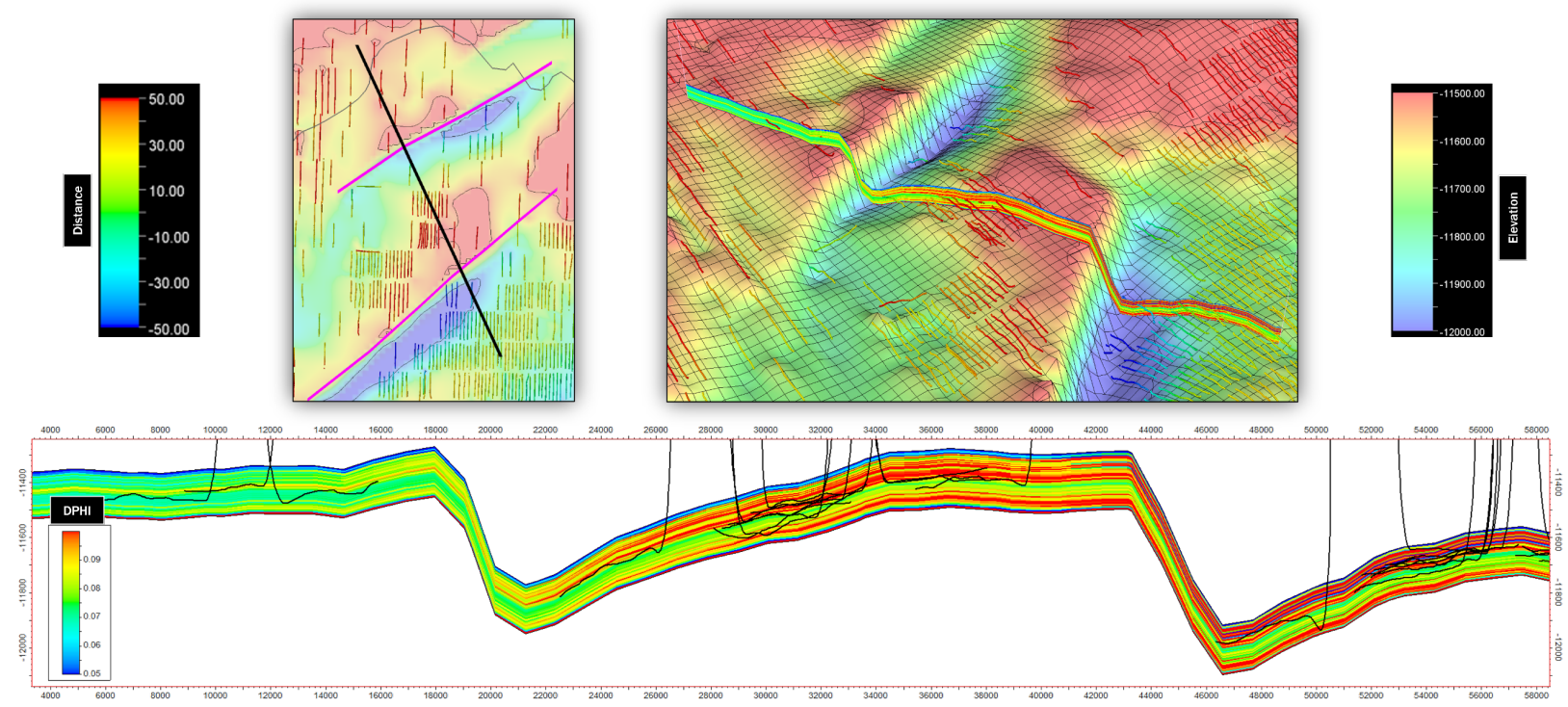

Figure 7 - Fault identification in Haynesville. Vertical exaggeration is 10x.

Figure 8 shows the identification of multiple faults by analyzing the well position log trend horizon of the Barnett shale in the Dallas area as described in Hennings et al (2019). The images show views to the northwest illustrating how horizon surfaces were created using the horizontal legs of more than 21,000 horizontal wells in the Mississippian Barnett Shale in the core production area of the Fort Worth basin. These horizon interpretations were used to map faults polygons in the Barnett shale, which in turn were converted to fault surfaces forming the basis for a sealed faulted framework including the Barnett and Ellenburger formations. 

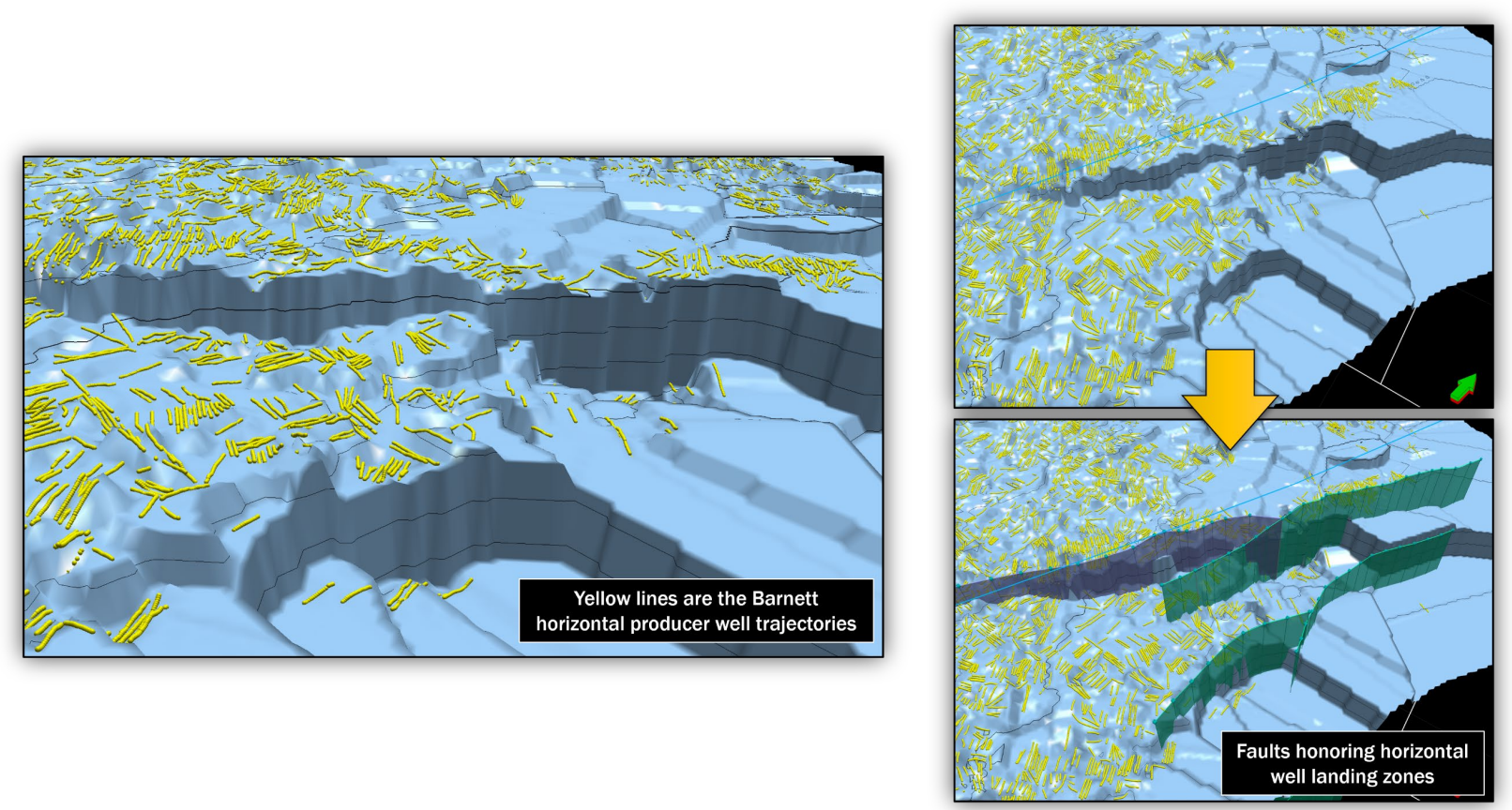

Figure 8 - Fault identification in Barnett Shale using a horizontal well position log trend surface. Vertical exaggeration is 10x.

I used the Schlumberger Petrel 3D modeling software to create a geocellular model based on a structural and stratigraphic framework which has been constructed using the well position log trend horizon for the Fort Worth basin Barnett shale horizontal producers. This 3D geomodel of the Fort Worth Basin allowed for the development of a detailed new interpretation of faults - as documented in Hennings et al (2019) and Gao et al (2021), that revealed far more basement-rooted normal faults than was previously known.

\subsection{Correcting stratigraphic horizons using horizontal well position log trend surfaces}

\subsubsection{Conformable gridding technique}

Jones (1986) describes the proper technique for conformable mapping, which starts by calculating the difference between the elevation values of a well top dataset and a designated reference horizon (e.g. a better-defined shallower horizon or a denser-data seismic horizon). Next, a trend surface for these residuals is calculated and added to the elevation values of the reference horizon to produce a new horizon surface. The resulting horizon both ties to the well tops and honors the shape of the reference horizon. In my well position log trend surface conformable mapping workflow, I create a surface that honors the trend of the horizontal well trajectories for each of the stratigraphic well top horizons. Figure 9a shows a well position log trend surface (purple line) mapped from horizontal leg segments of Hayneville producers. Figure 9b shows the top of Haynesville Shale (dashed red line) and the base of the Haynesville Shale (dashed blue line) horizon profiles mapped using only the stratigraphic well tops interpreted in vertical wells. The corrected top and base stratigraphic horizons defining the Haynesville Shale formation (solid lines) were generated by mapping horizon surfaces for those well tops conformable to the horizontal well position log trend surface.

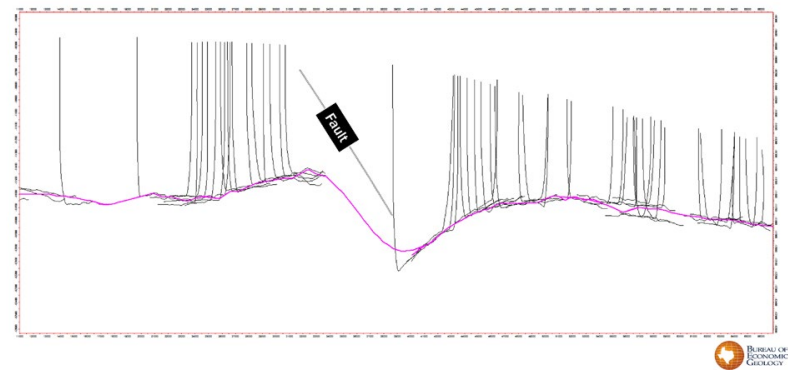

a) Cross-section showing well position log trend surface mapped from horizontal leg segments of Hayneville producers (purple). 


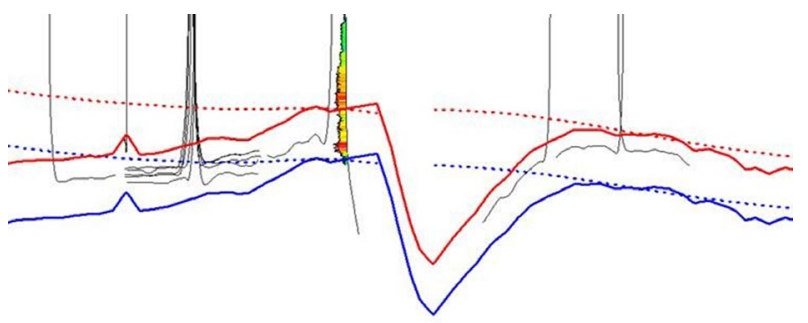

b) Cross-section showing a comparison of the Haynesville zone mapped using well tops (dashed lines) versus the zone mapped conformable to the well position log trend surface (solid lines) shown in Figure 9a. Note how the trend surface reveals the location of a major fault zone.

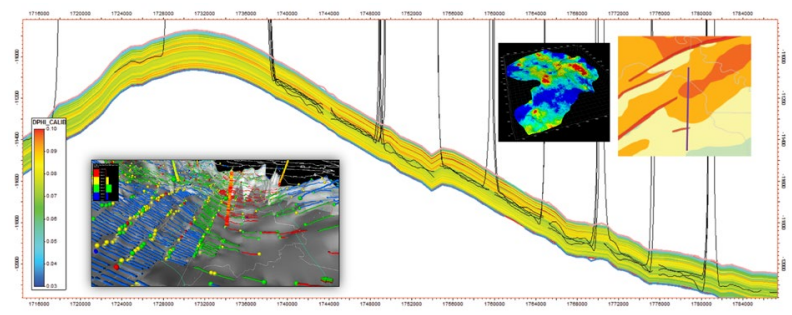

c) 3D geocellular model cross-section for the Haynesville Shale showing density-porosity distributed in layers based on a horizontal well position log trend-corrected stratigraphic framework.

Figure 9-The comparison of horizontal well landing zones from corrected horizons to original horizons. Vertical exaggeration is $10 x$.

\subsubsection{Structural fault framework and 3D corner point grid construction}

A geocellular model's structural framework consists of horizons, faults, and zones, which are combined to form sealed volumes. I started by interpreting fault polylines on both the top and bottom bounding horizon surfaces. Next, I modeled individual fault planes by fitting a triangular mesh surface to these top and base polylines. I established age-related truncation relationships between faults to define the fault-fault intersections. Horizon-fault lines were automatically created where horizons and faults intersect so that the stratigraphic surfaces are properly truncated. The structural framework construction resulted in a tetrahedral mesh bounded by horizons, faults, and model boundaries. The next step involved converting this mesh to either a structured 3D corner point grid or an unstructured grid which allows for the subdivision of the zones into individual layers along which various petrophysical and fluid attributes can be distributed.

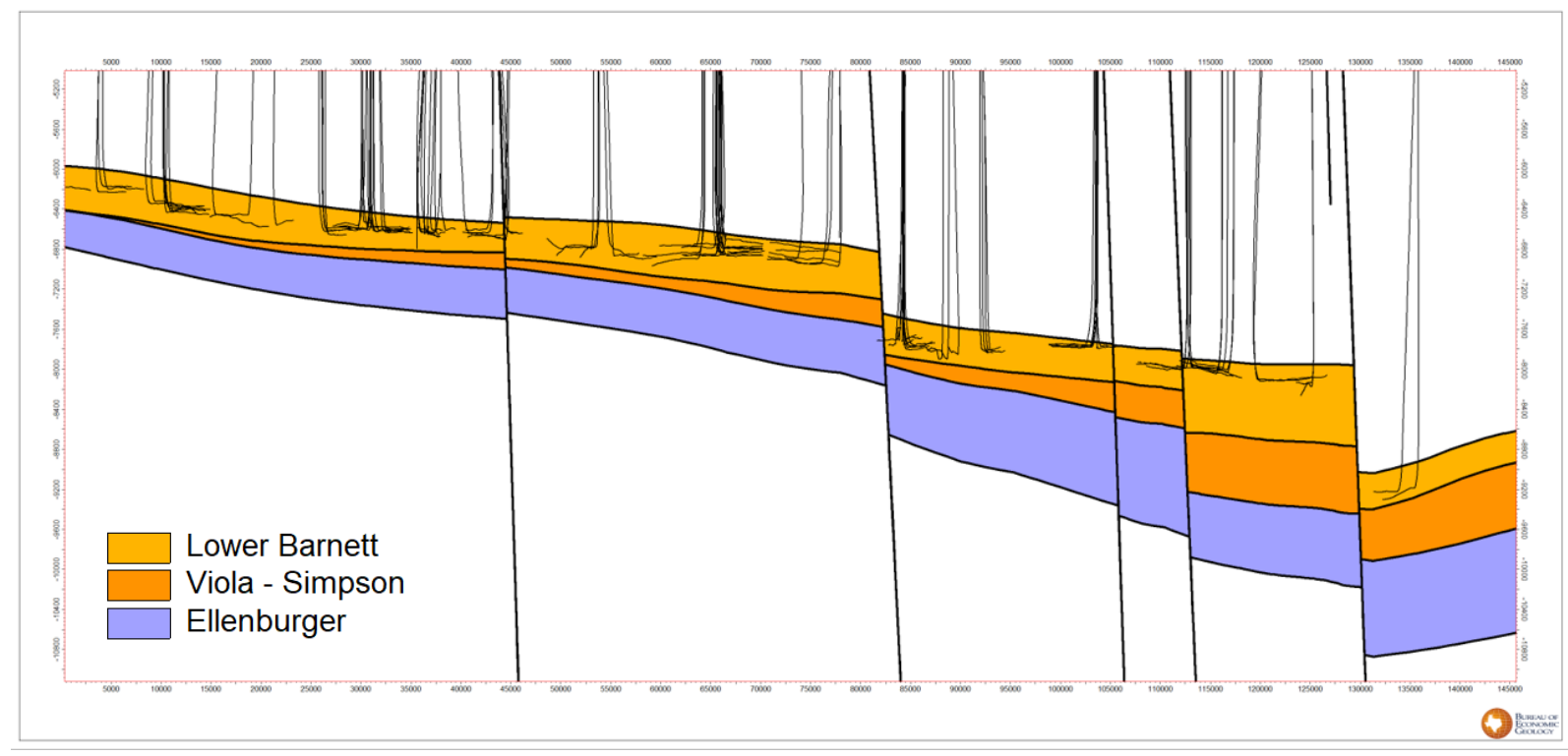

Figure 10 -Cross-section from sealed faulted framework 3D geocellular model showing horizontal producers completed in the Barnett Shale formation. Vertical exaggeration is 10x.

\subsection{Landing zone calculations}

The next step was calculating landing zones. First, I performed a zone averaging operation to determine the most-abundant stratigraphic zone value. This was necessary to determine the landing zone for the horizontal leg of each unconventional wellbore trajectory. Modern geomodeling tools have the capability to 
generate pseudo-well logs to sample the 3D grid properties. This step involved sampling the geocellular zone attribute along the well trajectory at one-foot measured depth increments. Figure 11 shows a model built for the Spraberry and Wolfcamp formations in the Midland Bain. The colors along the trajectories represent the zone traversals of the horizontal wells. Next, I defined two well log tops to be used in the zone-averaging operation. The first well log top is defined at the start of the horizontal leg of the wellbore, where the inclination values exceed 85 degrees from the vertical axis (heel of well). The second well log top is defined at the total depth value of the well, in measured depth (toe of well). Using a well log top based zone averaging technique, I ran a most-abundant algorithm analysis on the interval between the heel and toe tops, resulting in a single zone value for the horizontal leg of the wellbore. Finally, I assigned this value as a wellbore attribute, thus classifying the landing zone for the well, as shown in Figure 11b.

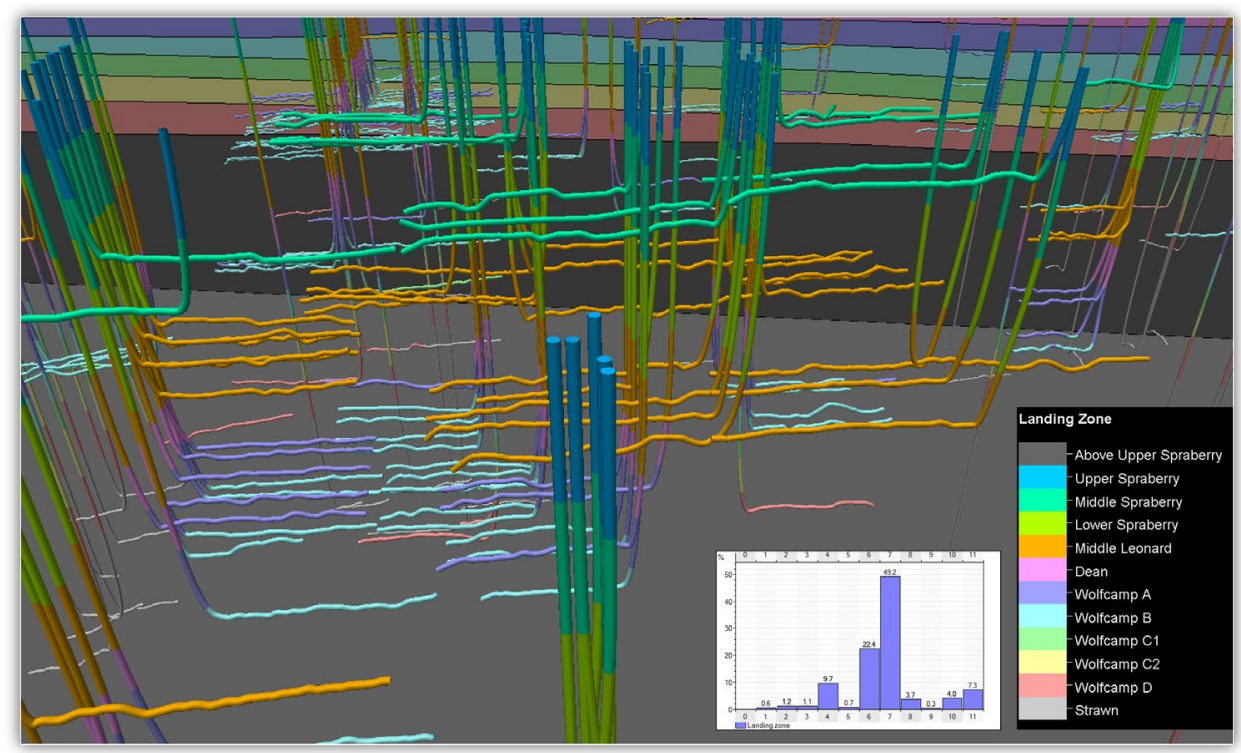

a) Horizontal wells colored by zone traversal sampled from $3 D$ geomodel zones.

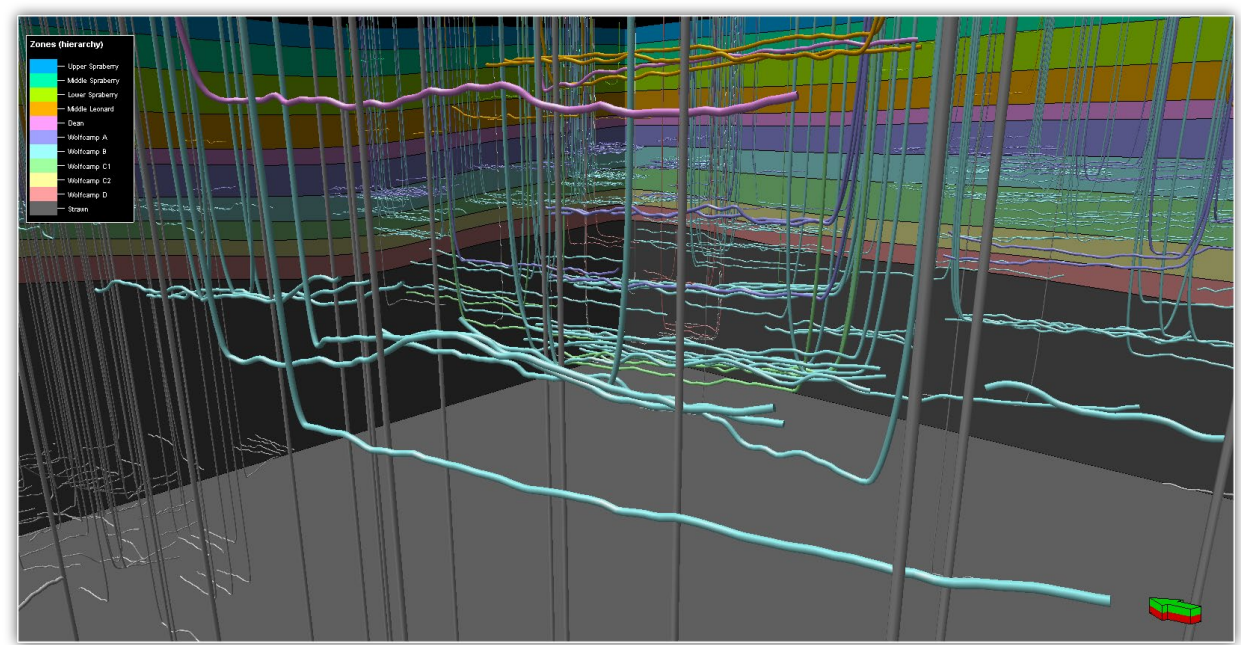

b) Wells colored by mostabundant zone occurrence between the heel and the toe of the horizontal legs.

Figure 11 - Calculation and classification of stratigraphic landing zones for well position logs. Vertical exaggeration is 10x. 


\subsection{Trend surface determination for multiple, stacked landing zones}

The Midland and Delaware Basin tight oil plays have been developed using horizontal producers targeting multiple landing zones for multiple formations. The following workflow outlines the modification to the well position log trend surface technique that we previously used for single-formation cases. The trend analysisbased stratigraphic correction workflow for multiple-formation and multiple landing zones can be summarized as:

1. Construct a 3D stratigraphic framework based on top and base horizons for the multiple formations containing the horizontal well trajectories (Figure 12a)

2. Build a layer framework with proportional thicknesses of approximately 5 feet.

3. Import the well position logs as a pointset into the 3D model (see Section 2.4).

4. Assign the 3D model stratigraphic layer value to each point in the well position log pointset using a 3D model back-interpolation method.

5. Create a histogram for the calculated stratigraphic layer values (Figure 12b).

6. Analyze the histogram to determine the various stratigraphic landing zones and define the ranges of layers for each. Assign a value to each of these landing zone groups (Figure 12f).

7. Assign the 3D model grouped landing zone value to each point in the well position log pointset using a 3D model pointset calculation.

8. Split the well position log pointset by grouped landing zone.

9. Calculate a trend surface for each of these grouped landing zones (see Section 2.4).

10. Map the stratigraphic well tops conformable to the grouped landing zone trend horizons.

11. Build the corrected stratigraphic framework using these new horizons. 


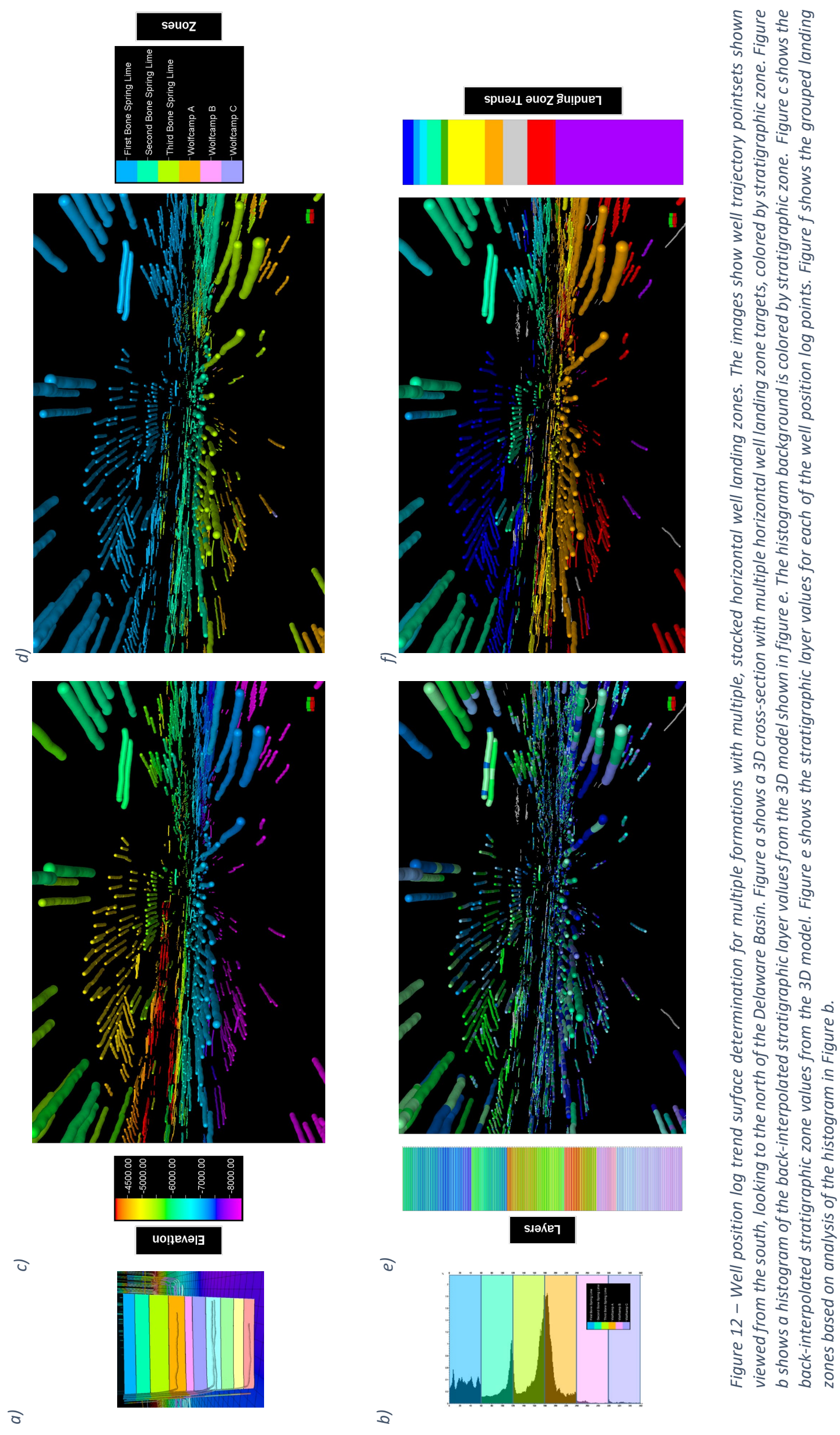




\section{Results}

Results of the stratigraphic horizon correction techniques are shown in Figure 13 (structure identification using well position log trend surface) and Figure 14 (comparison of corrected stratigraphic zones). Figure 13 shows an example from the Eagle Ford Shale. The original stratigraphic framework was based on the well log correlation of approximately 350 wells, with the interpretation of well tops for the Upper Eagle Ford, Lower Eagle Ford, and Buda limestone formations. I created a 3D geocellular model based on this stratigraphic model and imported 19,000 horizontal producers classified as Eagle Ford producers (IHS 2019). Investigation of the landing zones of the Eagle Ford producers revealed that approximately $60 \%$ of the wells did not fall within the model's Eagle Ford zone. Following the correction of the Buda Limestone and overlying Eagle Ford horizons by mapping them conformable to the horizontal well position log trend surface, the stratigraphic model was updated, resulting in $100 \%$ of the horizontal well trajectories now properly being classified with Eagle Ford landing zones.

The increased interpretation data density led to the clear definition of two distinctive Buda and Eagle Ford shale stratigraphic features; a) the Stuart City Reef margin, and b) the Karnes Trough. The Stuart City Reef margin of south-central Texas is a basinward dipping shelf edge complex consisting primarily of bioclastic carbonates, containing tight-gas reservoirs described by Waite (2009) and Loucks et al (2013). The lower Cretaceous Stuart City Reef trend runs parallel to the ancestral Gulf of Mexico basin boundary. The Karnes Trough is a graben system controlled by a series of basinward and landward dipping faults. These area of syndepositional faults shows signs of increased accommodation in the topographic low (Workman 2013). The Karnes Trough is the region of highest oil production in the Eagle Ford Shale and is located in Karnes County to the southwest of the San Marcos Arch.

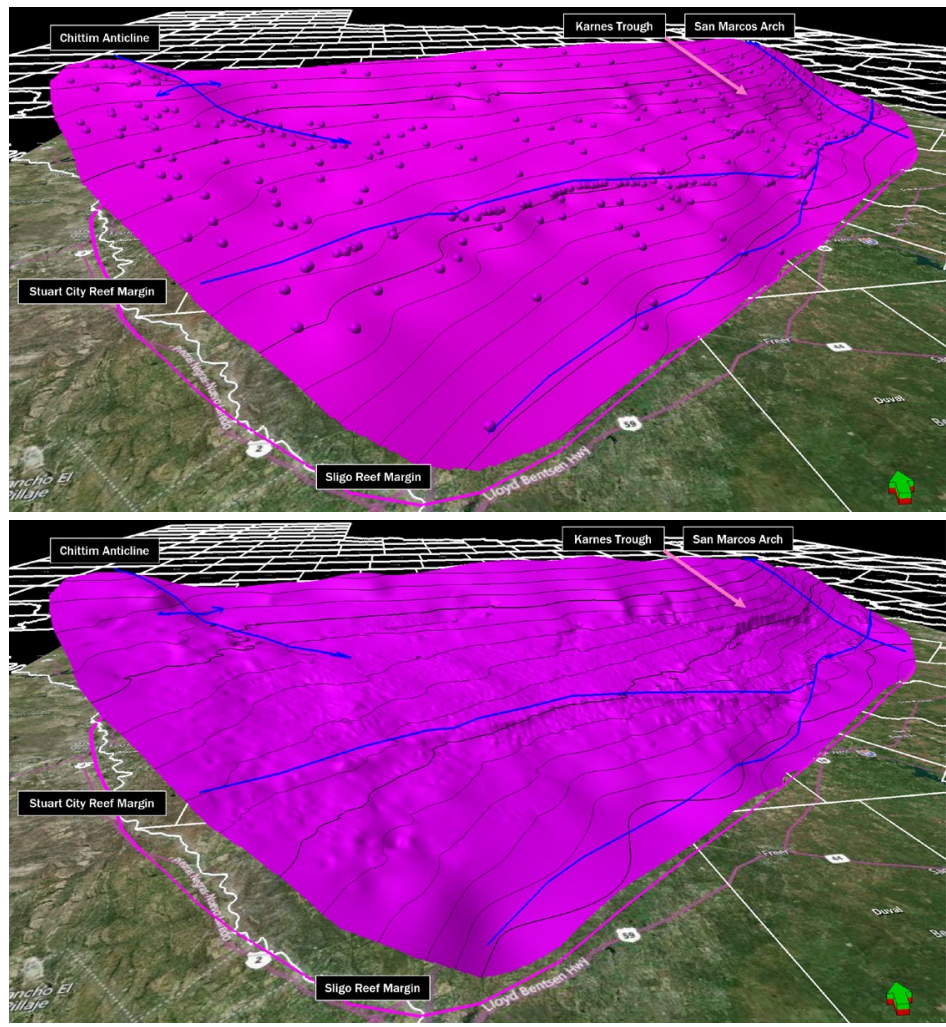

a) Top of Buda Limestone mapped using 350 well tops

b) Top of Buda Limestone mapped conformable to well position log trend surface for 19,000 Eagle Ford horizontal producers. 


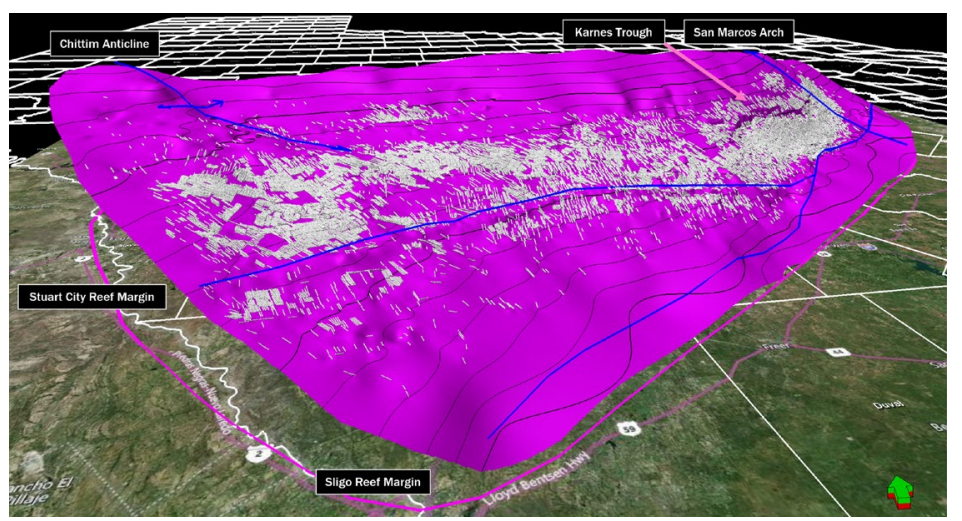

c) Top of Buda Limestone mapped conformable to trend surface showing horizontal well position logs in white.

Figure 13-Buda limestone stratigraphic horizon (purple) viewed in 3D from the southwest. Figure 13a shows the horizon mapped using 350 well tops obtained using regional well log correlation. Figure $13 \mathrm{~b}$ shows the horizon mapped conformable to the well position log trend surface for 19,000 Eagle Ford horizontal producers. Figure 13c adds the horizontal well position logs for the Eagle Ford producers in white. Note that the Stuart City reef margin and Karnes Trough structures are clearly highlighted by the horizon mapped conformable to the well position log trend surface. Vertical exaggeration is 10x.

Figure 14 (comparison of corrected stratigraphic zones) shows a north to south dip-cross section comparing the two 3D geomodels based on the differing stratigraphic frameworks. This northwest-southeast cross-section shows the Eagle Ford zone based on the 350-well stratigraphic framework in red, and the Eagle Ford zone based on these tops mapped conformable to a well position log trend surface based on approximately 19,000 Eagle Ford horizontal wells.

In this Eagle Ford example, the well position log trend surface conformable mapping revealed a correction of approximately 540 feet in an area where the Eagle Ford thickness is estimated to be 160 feet in true vertical thickness (TVT).

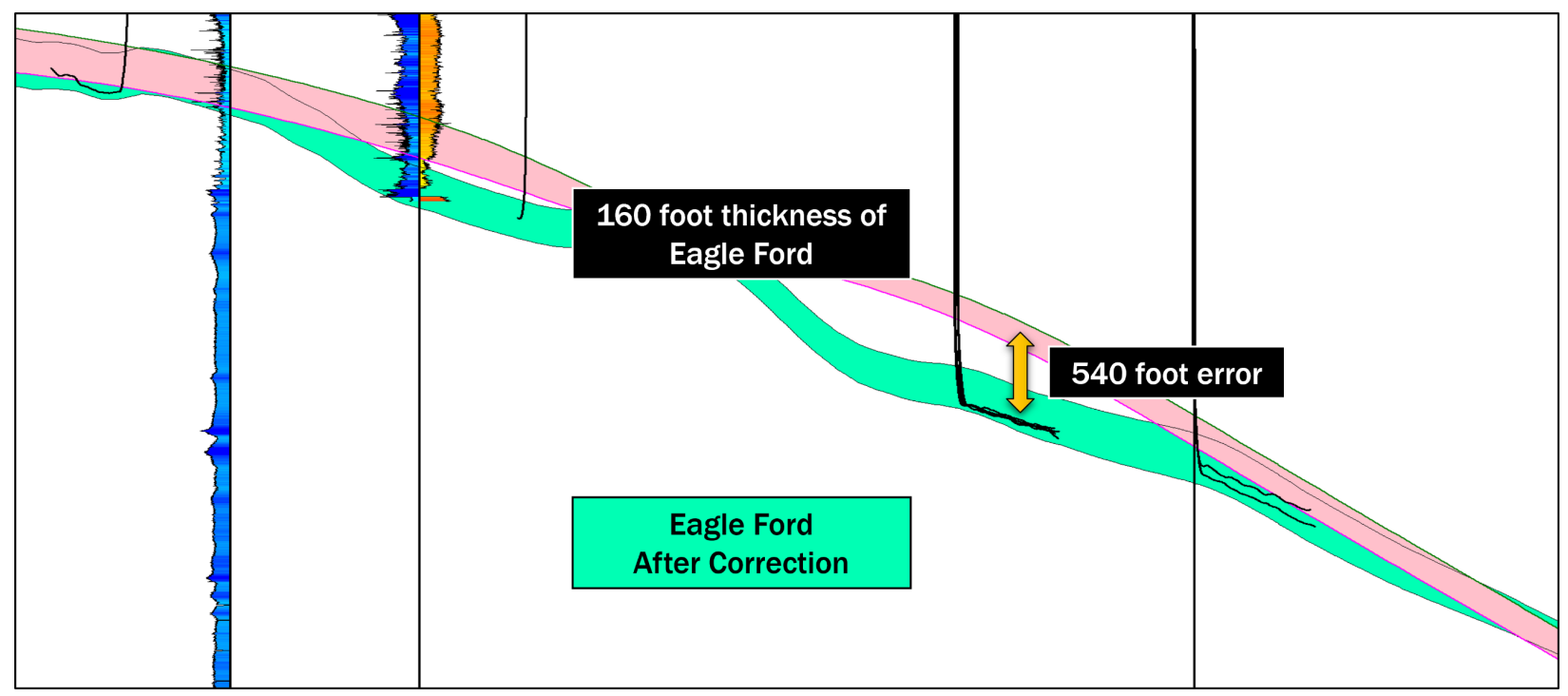

Figure 14 - Cross-section showing a comparison of the Eagle Ford zone mapped using 350 well tops (red) versus the Eagle Ford zone mapped conformable to the well position log trend surface (green). In this cross-section, the Eagle Ford is approximately 160 feet thick. Note the difference of 540 foot between the red and green Eagle Ford modeled zones. Vertical exaggeration is $10 x$.

Figure 15 shows a north to south geomodel dip-cross section demonstrating the results of the stratigraphic horizon correction using the well position log trend surface conformable mapping technique. The geocellular model attribute RHOB was averaged using vertical well density log curves and distributed along multiple 5 -foot-thick layers for the Fayetteville Shale interval. The vertical faults were obtained from analysis of the well position log trend analysis. Inset images show the top of the faulted Fayetteville Shale horizon. Horizontal Fayetteville Shale wells landed in the targeted production zone are shown as black trajectories. 


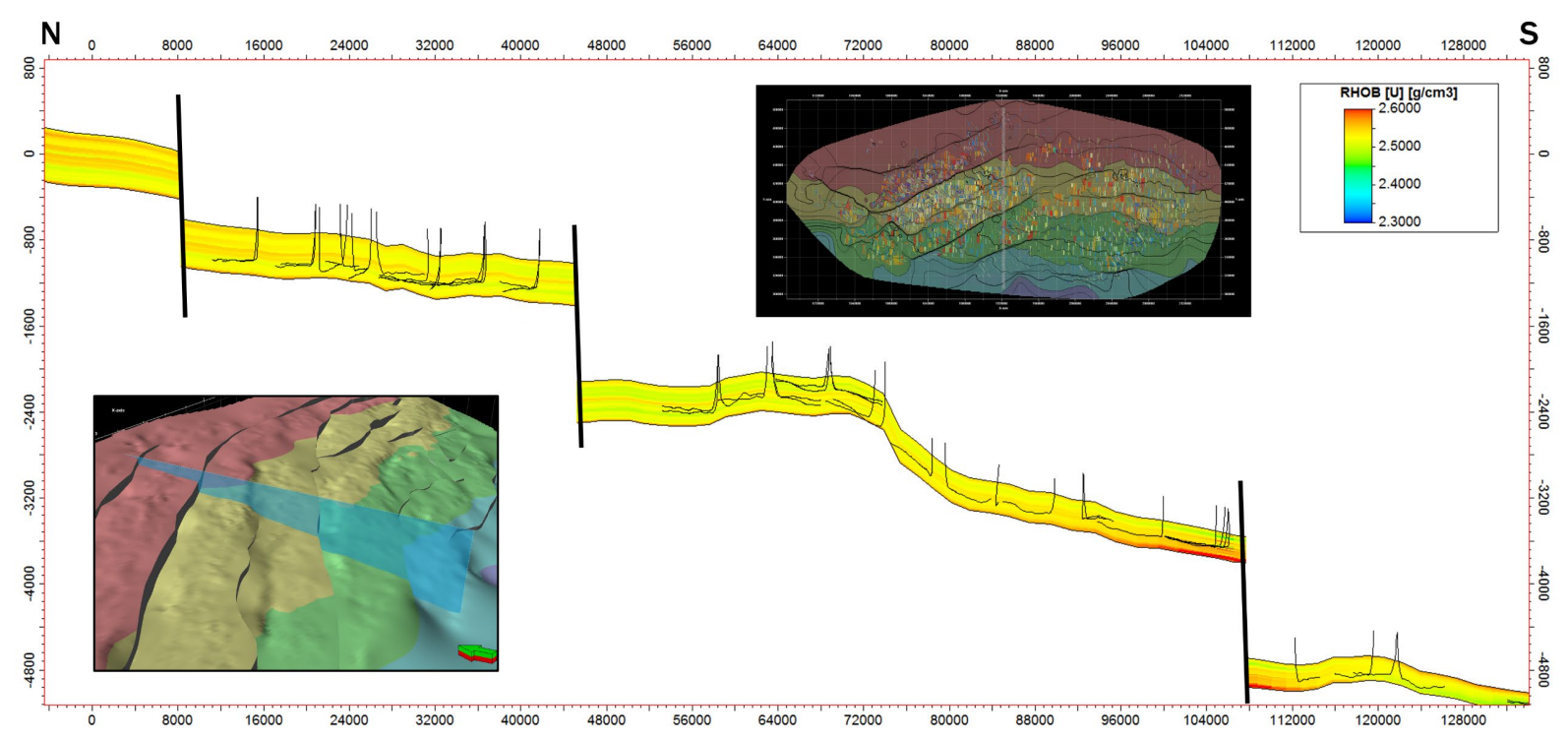

Figure 15 - 3D geocellular model cross-section for the Fayetteville Shale showing density distributed in layers based on a horizontal well position log trend-corrected stratigraphic framework. Vertical exaggeration is 10x.

\section{Discussion}

\subsection{Geosteering data integration}

\subsubsection{Drawbacks of Well log correlation-based Stratigraphic Frameworks}

Stratigraphic frameworks of regional geological reservoir models are typically based on interpretations obtained from one or several 3D seismic surveys. These seismic surveys are rarely made available for research. In order to study a regional unconventional play, oil and gas exploration and production companies usually combine multiple 3D seismic surveys into a single project, map the stratigraphic horizons and structural features (e.g. faults) across these surveys in the time domain, and then construct velocity models to convert the horizon surfaces to the depth domain as discussed in Bayer (2016). The next step is to calibrate the horizons using both vertical and horizontal wells.

Those who do not have access to 3D seismic volumes needed for seismic horizon interpretation use well log correlation methods instead to define stratigraphic zones. However, this can lead to inaccurate models. In the case of the Bakken study, Hamlin et al (2017) defined the Bakken stratigraphic framework by interpreting well log tops in 885 correlation wells distributed throughout the study area. Following the construction of a 3D geocellular model, as described in the geomodeling section by the author in Ikonnikova et al (2018), the horizontal wells were displayed together with stratigraphic layers based on the well log interpretation process. Figure 17 show this zonation using solid colors for the layers. The horizontal wells in the vicinity of the cross-section are projected into the line of section and are shown as purple lines. In comparing the horizontal well trajectories with the colored zone interpretation, based on the 885 correlation wells, we show that there is a significant discrepancy between the geological layer structure and the horizontal producer landing zones. The figure shows that many of the horizontal wells do not coincide with the Bakken target zone. Analysis of the landing zones for all the horizontal wells in the 3D model revealed that over $40 \%$ of these wells, reported as Bakken producers, fall outside of the Bakken target zone. This indicates that this geological model is not accurate enough to characterize the structure variations in the horizons across the study area.

\subsubsection{Advantages of using Geosteering Data based on Pre-drill Seismic and Stratigraphic Interpretation}

Southcott \& Harper (2014) observed that Bakken geosteering errors in the Williston Basin were reduced by $90 \%$ from mid-2012 to early 2013 . They attributed this improvement to the use of 3D seismic data. This 
improved geosteering process consists of the interpretation of the target landing zones using accurate well top correlations combined with interpretation of depth-converted seismic.

Unconventional reservoirs are developed using horizontal wells planned using pre-drill geological earth models. These horizontal wells are guided to their landing zone targets using a process called geosteering. Jackson et al (1998) defines geosteering as the ability to quantitatively identify and respond to changes in the observed geology during horizontal well drilling operations. This geological information is derived from an analysis of measured petrophysical log data obtained while drilling. Modern geosteering software solutions combine real-time measurement- or logging-while-drilling (MWD/LWD) well log data acquisition with the ability to compare these measurements to forward-modeled logs based on a dynamically changing earth model. Examples of MWD/LWD logs include gamma ray, resistivity, rate of penetration, and image logs. Geosteering operators correlate these horizontal well logs to vertical well logs in type-wells and offset wells by projecting the horizontal logs into a true vertical depth space. The geosteering workflow enables operators to identify potential problems preventing the well from staying within the target zone to minimize the need for trajectory adjustments.

Tadjer et al (2021), and references therein, describe how stratigraphic based geosteering has become ubiquitous for North American horizontal wells. Tadjer analyzed the results of a geosteering competition (ROGII Geosteering World Cup), conducted in November 2020, involving 131 geosteerers from around the world who were given several conventional and unconventional geological targets and asked to use the commercial software StarSteer, developed by ROGII Inc, to develop real-time geosteering solutions. Their analysis of the population data of well trajectories and interpretations made by the finalists of the event revealed that the percentage in-target is mostly correlated to the geosteerer's trust in the pre-drill geological model, interpretation quality (comparison to synthetic target layer boundary) and the number of segments (sections defined with interpreted fixed dip). Investigation of the superimposed gosteering-derived well trajectories on the synthetic target zones reveals that the vast majority of the geosteering interpretations land in the target zones, especially when taking typical vertical extents of hydraulic fractures into account. They concluded that knowledge of pre-drill information quality can be highly beneficial, confirming the value of building accurate integrated 3D geological models.

\subsubsection{Limitations of Geosteering Data}

Pitcher \& Jackson (2012) note that lateral heterogeneity, poor sensor measurements, and high rates of penetration are all limitations of the geosteering methodology. They nonetheless conclude that even in areas of structural complexity, the geosteering process is capable of accurately identifying the structural and stratigraphic position of the well while it is being drilled. Viens (2019) acknowledges a large contributing factor to true vertical depth (TVD) measurements in horizontal wells by comparing standard 90-foot directional surveys to the more accurate continuous inclination tools. He observed up to 50 -foot vertical thickness differences between the two methods due to error accumulations associated with conventional 90-foot surveys.

Wellbore directional surveys obtained from LWD/MWD operations can be corrected in real-time by 50 to 60 percent using In-Field geomagnetic Referencing (IFR) and Multi-Station Analysis (MSA), as described by Maus (2015). DeVerse and Maus (2016) compared 138 corrected to original well trajectories in Eagle Ford Shale. They noted that the lateral Root Mean Square (RMS) difference of the horizontal total depth points was 78 feet with a maximum difference of 269 feet.

Figure 16 shows an example of horizontal producers completed in the Fort Worth basin Barnett Shale. The white well trajectories are encircled by a red cone representing progressively increasing positional uncertainty. The diameter of the red cones is 50 feet at the total depth of the wells. 


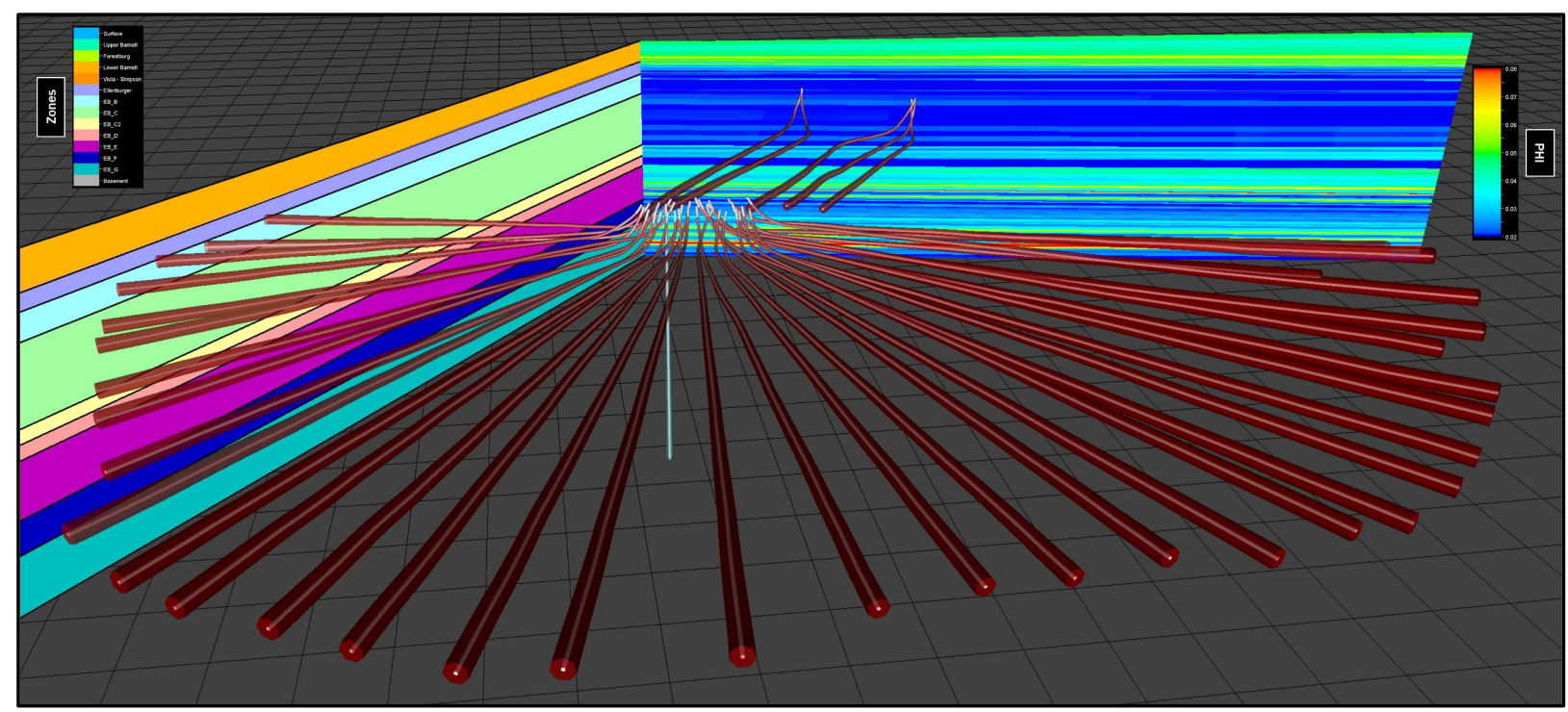

Figure 16 - Horizontal producers in the Fort Worth basin Barnett Shale showing directional survey positional error cones. Crosssections showing both 3D geomodel porosity and geological formations are shown in the background. The grey horizon is the basement surface of the Fort Worth basin. Vertical exaggeration is $1 x$.

\subsection{Correlation network density improvements}

Taking these uncertainties related to geosteering and horizontal well surveying into account, we proceeded with the assumption that horizontal well position logs resulting from the geosteering operations were accurate enough to map general surface trends for single- and multiple landing zone field development scenarios.

Using the processes described in the methods section, we created a new stratigraphic framework using horizons mapped with formation tops from more than 8,000 correlation wells in the Bakken study area, an order of magnitude greater than the previous well log correlation process. These additional formation tops were obtained from the IHS MarkIt Enerdeq Browser. Figure 17 shows the corrected stratigraphic framework as solid black lines. The horizontal well trajectories (purple) are shown to fall within the corrected Bakken stratigraphy. Analysis of the landing zones for all the horizontal wells in this corrected 3D model revealed that all previously incorrect horizontal landing zones are now properly assigned to the Bakken target zone. This result proved the value of significantly increasing the number of correlation wells in a much denser well control set, resulting in a significantly more accurate stratigraphic interpretation. Geomodels utilizing denser correlation networks are much better suited to distribute the petrophysical parameters derived from the vertical wells to the areas containing the horizontal producers in unconventional plays like the Bakken. 


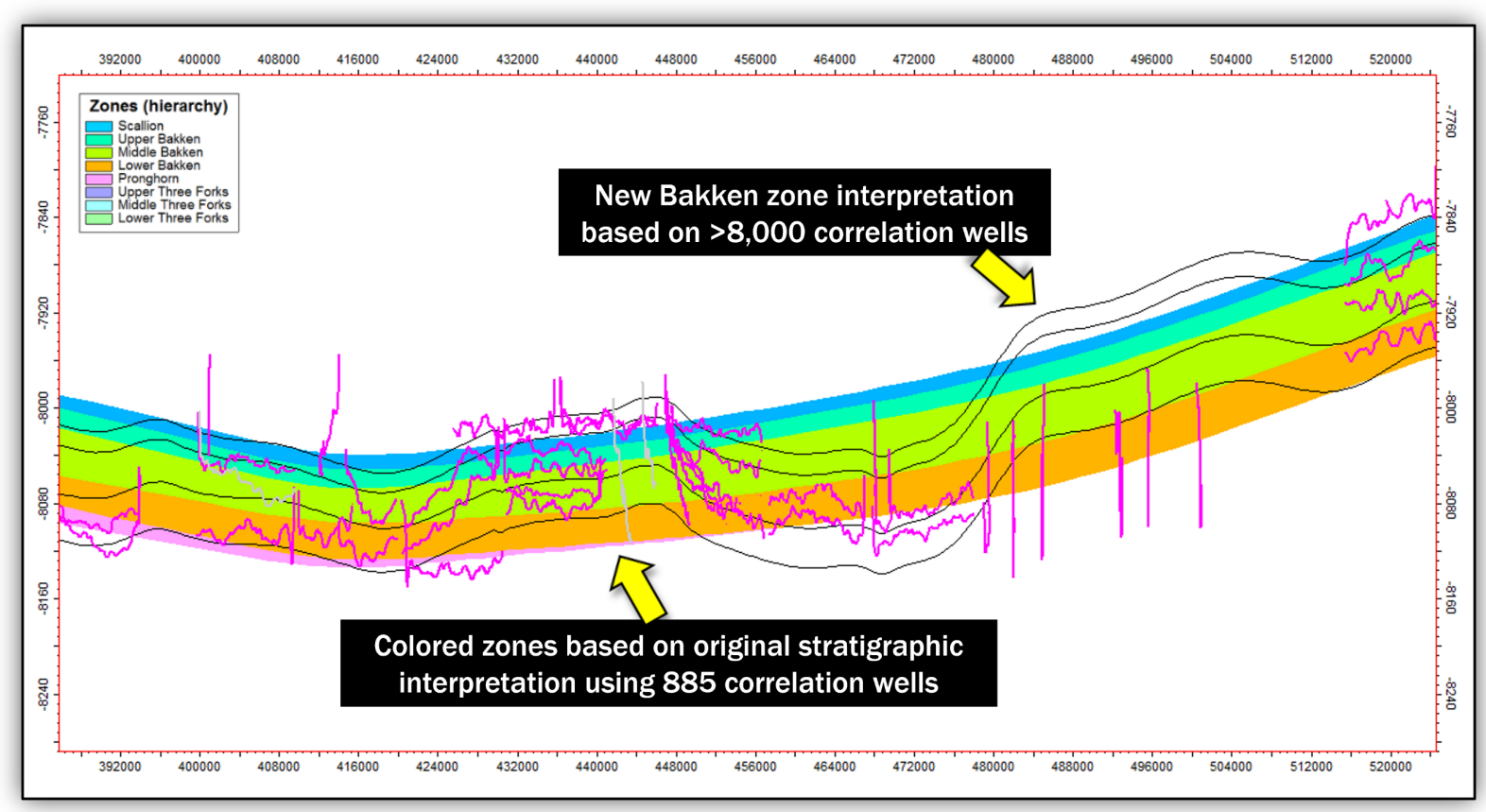

Figure 17 - Difference in stratigraphic framework construction between well tops from $>8,000$ wells vs 885 . Note how the horizontal well trajectories (purple) are better captured using the stratigraphic correlations generated using the more densely spaced vertical wells (black lines) when compared to the original interpretation, based on 885 wells.

\subsection{Well position log trend surface-based frameworks}

One of the advantages of integrating wellbore trajectories into geocellular models is that it enables a straightforward calculation of vertical distances between well trajectories and stratigraphic horizons. This allows for the efficient calculation and analysis of landing zones for thousands of horizontal producers in shale and tight oil reservoir studies. Conformable mapping techniques, available in many 3D geomodeling software solutions, allow for the calculation and application of trend surfaces for horizontal wells position logs. Combining these techniques lead to the development of more accurate stratigraphic frameworks (Figure 13).

It is critical to integrate both vertical and horizontal wells at the same scale and resolution to perform regional studies of shale and tight oil plays. The goal of analyzing horizontal well production performance requires geomodels containing petrophysical and fluid distributions obtained from vertical wells. If the stratigraphic framework is unable to accurately model the interwell layer structures, correlation between vertical well attribute distributions and horizontal well productivity becomes impossible, preventing the transition from 2D map-based analysis to more advanced 3D geomodel-based analysis (Figure 14 \& Figure 15).

Rijks \& Jauffred (1991) noted that first derivative-based dip magnitude and dip azimuth operations performed on horizon surfaces can highlight subtle faults having a displacement significantly less than the size of a seismic wavelet. Mondt (1993) described how areal analysis of combined dip-azimuth attribute displays for seismic horizons can be used to identify faults and sedimentary features.

Jones et al (1992) identified the problem with independent mapping of conformable horizons which ignores changes in structural complexity due to decreased wellbore data density with depth. They observed that ignoring additional stratigraphic relationship information can create maps that are not geologically consistent. 
Using the fault-identification capabilities of the well position log trend analysis in combination with conformable mapping techniques leads to more accurate stratigraphic frameworks and 3D geomodels (Figure 15).

\subsection{Validation of methodology by comparison to 3D seismic interpretation}

Figure 18 shows the ability of the well position log trend surface-based stratigraphic framework to both accurately capture the vertical landing zones of the horizontal producers as well as the overall dip trend of the Eagle Ford formation. The green Eagle Ford stratigraphic zone scenario uses the same 350 well log tops as were used to map the red Eagle Ford zone and is mapped conformable to the well position log trend surface. Comparing the green Eagle Ford zone with the background depth-seismic shows that the correction technique is able to match the main structural features evident in the 3D seismic.

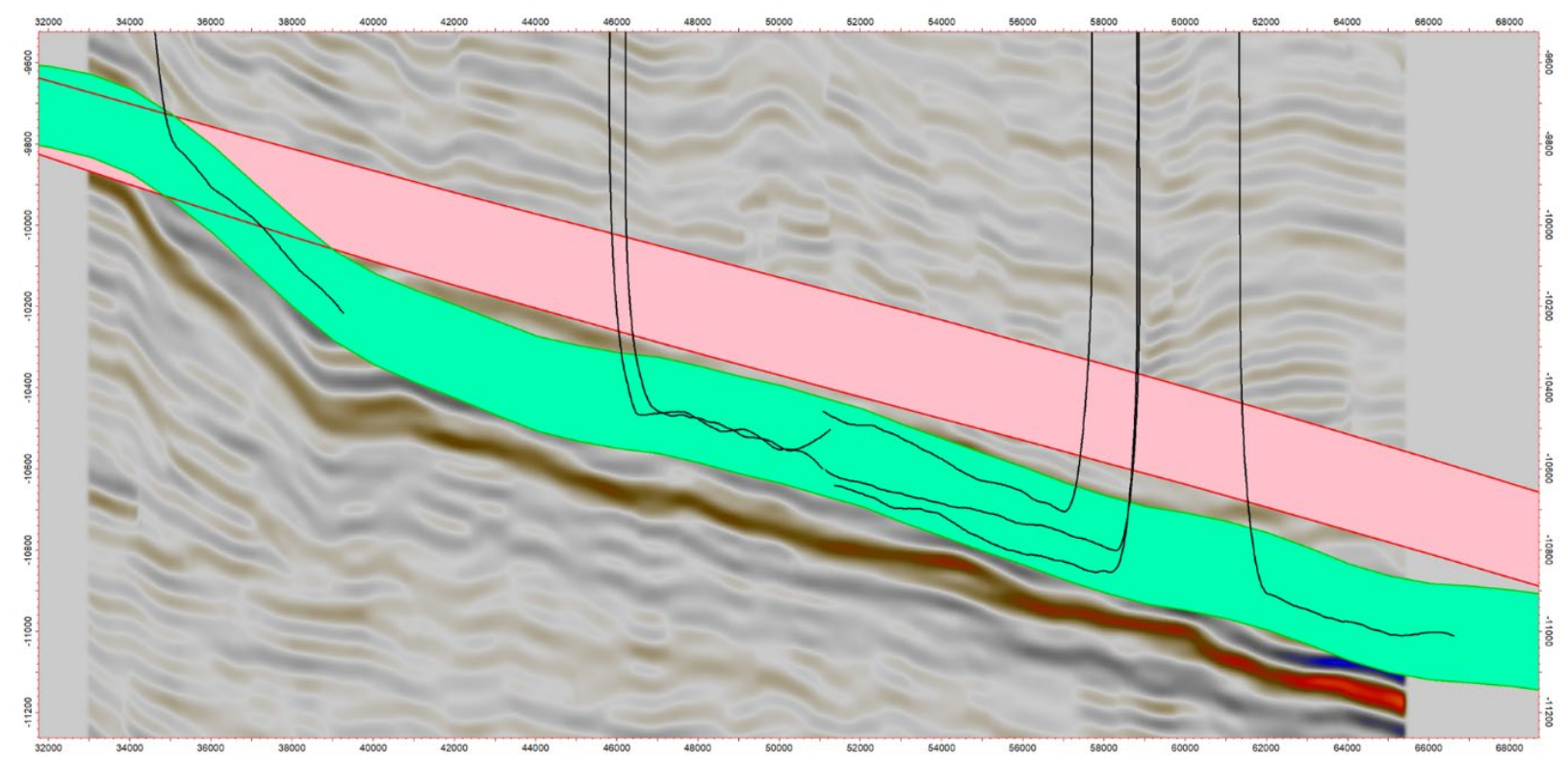

Figure 18 - North-south seismic cross section showing a comparison of the Eagle Ford stratigraphic frameworks based on 350 well tops (red) and the stratigraphic framework based on the well position log trend surface correction method (green). Vertical exaggeration is $10 x$. 


\section{Conclusions}

Modern hydrocarbon exploration and development of unconventional plays results in rich datasets that can be used to build detailed models that capture the complexity of basin fill history and for understanding the 3D facies architecture. Thus far the published literature appears to lack papers that outline a methodology for using data from well position logs in areas of dense horizontal drilling. Future work will use this approach, integrated with 3D seismic, to develop geomodels that can be used to gain a better understanding of the structural and sedimentologic evolution of the basin.

The lack of publicly available 3D seismic surveys is an impediment to researchers attempting to construct accurate subsurface geocellular models in the presence of faults. The methods analysis presented in this paper demonstrated that:

1) Integrating geosteering-derived results highlights the drawbacks of the overreliance on well log correlation-based stratigraphic frameworks that often undersample the total number of correlation wells available in a shale or tight-oil basins, which leads to significant inaccuracies in landing zone calculations.

2) Well log correlation of detailed stratigraphic zones using densely spaced vertical wells significantly improves the accuracy of stratigraphic framework interpretation.

3) Conformable mapping of trend surfaces generated using geosteered 3D horizontal well position logs improves the accuracy of stratigraphic horizons.

4) Residual analysis of regional and local horizontal well trend surfaces can be used to identify faults.

The conclusion of this study is that in the absence of available 3D seismic surveys, the application of the described stratigraphic horizon correction techniques is of critical importance to the quality of subsurface geological models used for reserves determination in shale gas and tight oil basins.

\section{Declaration of competing interest}

The author declares that he has no known competing financial interests or personal relationships that could have appeared to influence the work reported in this paper.

\section{Acknowledgements}

The author thanks both lan Duncan and Frank Male for their valuable insights, suggestions and reviewing previous versions of this paper. The geomodeling projects were partially funded by the U.S. Department of Energy project "Update and Enhancement of U.S. Shale Gas Outlooks" and the Alfred P. Sloan Foundation project "The Role of Shale Oil in the U.S. Energy Transition" (Principal Investigator, Scott Tinker). Analysis was performed using the Petrel 3D modeling software obtained through the generous donation to the University of Texas by Schlumberger. Mark Shuster, BEG Deputy Director, reviewed the final version and made useful comments. This paper is published with the permission of the Director of the BEG.

\section{References}

Bayer, W.S., Wunderle, M., Araujo, E., Alcalde, R., Yao, C., Suhy, F., Jo, T., Bases, F., Sani, A.M., Ma, Y. and Bansal, A., 2016, August. Geological and Geomechanical Modeling of the Haynesville Shale: A Full Loop for Unconventional Fractured Reservoirs. In Unconventional Resources Technology Conference, San Antonio, Texas, 1-3 August 2016 (pp. 2112-2137). Society of Exploration Geophysicists, American Association of Petroleum Geologists, Society of Petroleum Engineers.

Chopra, S. and Marfurt, K., 2007. Curvature attribute applications to 3D surface seismic data. The Leading Edge, 26(4), pp.404-414.

Dommisse, R., Male, F., Scott Hamlin, H. and Sivila, L., 2018, September. The value of building a multiscale, regional geomodel for reserves assessment of the Midland Basin. In Unconventional Resources 
Technology Conference, Houston, Texas, 23-25 July 2018 (pp. 709-719). Society of Exploration Geophysicists, American Association of Petroleum Geologists, Society of Petroleum Engineers.

Enerdeq Browser from IHS Markit (https://penerdeq.ihsenergy.com)

Energy Information Administration (EIA) Natural Shale Gas Proved Reserves as of December 31, 2019. Accessed from https://www.eia.gov/dnav/ng/ng enr shalegas dcu NUS a.htm

Energy Information Administration (EIA) Crude Oil Proved Reserves as of December 31, 2019. Accessed from https://www.eia.gov/dnav/pet/pet crd pres a EPCO R01 mmbbl a.htm

Gao, S., Nicot, J.P., Hennings, P.H., La Pointe, P., Smye, K.M., Horne, E.A. and Dommisse, R., 2021. Low pressure buildup with large disposal volumes of oil field water: A flow model of the Ellenburger Group, Fort Worth Basin, northcentral Texas. AAPG Bulletin, 105(12), pp.2575-2593.

Hamlin, H.S., Smye, K., Dommisse, R., Eastwood, R., Lemons, C.R. and McDaid, G., 2017, September. Geology and petrophysics of the Bakken unconventional petroleum system. In Unconventional Resources Technology Conference, Austin, Texas, 24-26 July 2017 (pp. 1294-1307). Society of Exploration Geophysicists, American Association of Petroleum Geologists, Society of Petroleum Engineers.

Hennings, P.H., Lund Snee, J.E., Osmond, J.L., DeShon, H.R., Dommisse, R., Horne, E., Lemons, C. and Zoback, M.D., 2019. Injection-induced seismicity and fault-slip potential in the Fort Worth Basin, Texas. Bulletin of the Seismological Society of America, 109(5), pp.1615-1634.

IHS Enerdeq data access, 2019. Well header and well directional survey downloaded for Formation Producing Name classified as Eagle Ford.

Ikonnikova, S.A., Smye, K., Browning, J., Dommisse, R., Gülen, G., Hamlin, S., Tinker, S., Male, F., McDaid, G. and Vankov, E., 2018. Final Report on Update and Enhancement of Shale Gas Outlooks (No. DOE-BEG0026962). Bureau of Economic Geology, University of Texas at Austin.

Jones, T.A. and Johnson, C.R., 1983. Stratigraphic relationships and geologic history depicted by computer mapping. AAPG bulletin, 67(9), pp.1415-1421.

Jones, T. A., D. E. Hamilton, and C. R. Johnson, 1986, Contouring geologic surfaces with the computer: New York, Van Nostrand Reinhold, 314 p.

Loucks, R.G., Lucia, F.J. and Waite, L.E., 2013. Origin and description of the micropore network within the Lower Cretaceous Stuart City Trend tight-gas limestone reservoir in Pawnee Field in South Texas.

Maus, S. and DeVerse, J.S., 2015, September. Magnetic Referencing and Real-Time Survey Processing Enables Tighter Spacing of Long-Reach Wells. In SPE Liquids-Rich Basins Conference-North America. OnePetro.

Mondt, J.C., 1993. Use of dip and azimuth horizon attributes in 3D seismic interpretation. SPE formation evaluation, 8(04), pp.253-257.

Pitcher, J., Clegg, N., Burinda, C., Cook, R., Knutson, C., Scott, M. and Løseth, T., 2010, February. Advances in Geosteering Technology: From Simple to Complex Solutions. In IADC/SPE Drilling Conference and Exhibition. OnePetro.

Pitcher, J. and Jackson, T., 2012, March. Geosteering in unconventional shales: Current practice and developing methodologies. In SPE/EAGE European Unconventional Resources Conference and Exhibition. OnePetro. 
Rijks, E.J.H. and Jauffred, J.C.E.M., 1991. Attribute extraction: An important application in any detailed 3D interpretation study. The Leading Edge, 10(9), pp.11-19.

Sawaryn, S.J. and Thorogood, J.L., 2003, October. A compendium of directional calculations based on the minimum curvature method. In SPE annual technical conference and exhibition. OnePetro.

Smye, K., Hamlin, H., Eastwood, R. and McDaid, G., 2019. Variability of Geologic Properties of Shale Gas and Tight Oil Plays. Gulf Coast Association of Geological Societies, 8, pp.191-209.

Southcott, A. and Harper, H., 2014, August. 3-D Seismic Proves Its Value in Bakken Geosteering. In SPE/AAPG/SEG Unconventional Resources Technology Conference. OnePetro.

Tadjer, A., Alyaev, S., Miner, D., Kuvaev, I. and Bratvold, R.B., 2021, December. Unlocking the Human Factor: Geosteering Decision Making as a Component of Drilling Operational Efficacy. In Unconventional Resources Technology Conference, 26-28 July 2021 (pp. 1395-1410). Unconventional Resources Technology Conference (URTeC).

Tearpock, D.J. and Bischke, R.E., 2002. Applied subsurface geological mapping with structural methods. Pearson Education.

Tearpock, D., Bischke, R., Metzner, D.C., Brenneke, J., Bischke, R.E. and Metzner, D., 2020. Applied Threedimensional Subsurface Geological Mapping: With Structural Methods. Pearson.

Viens, C., 2019, July. Azimuthal gamma imaging and continuous inclination applications to spatial and stratigraphic wellbore placement in the Southern Midland Basin. In SPE/AAPG/SEG Unconventional Resources Technology Conference. OnePetro.

Waite, L.E., Scott, R.W. and Kerans, C., 2007. Middle Albian age of the regional dense marker bed of the Edwards Group, Pawnee Field, south-central Texas.

Waite, L.E., 2009. Edwards (Stuart City) shelf margin of south Texas: new data, New Concepts. Tulsa Geological Society, Tulsa, Oklahoma, USA, 9.

Workman, S.J., 2013. Integrating depositional facies and sequence stratigraphy in characterizing unconventional reservoirs: Eagle Ford Shale, South Texas (Doctoral dissertation, Western Michigan University).

\section{List of Figures}

Figure 1 - Integrated 3D geocellular reservoir models of six shale gas basins including the Eagle Ford, Bakken, Barnett, Fayetteville, Haynesville, Marcellus, and two tight oil basins including the Midland Basin and Delaware Basin.2

Figure 2 - Log signature map of well log curves in the Bakken study. Gamma ray well log curves are shown increasing from left to right. The middle Bakken formation is shown as a zone with relatively lower gamma ray values. $\quad 3$

Figure 3 - Horizontal well position log trend surface. Horizontal well position logs are shown in red. The inset image shows the surface generated from the position logs prior to applying fault traces in the surface modeling algorithm. The main image shows the faulted horizontal well position log trend surface. Vertical exaggeration is $10 x . \quad 4$

Figure 4 - Dip-angle attribute display for well position log trend surface. Vertical exaggeration is 10x. 4

Figure 5 - In the left image is a Haynesville horizontal well with position log points colored by vertical distance to of top of the Haynesville stratigraphic zone. The right image shows the distance of the horizontal well position log points to the position log trend surface based on all of the points in the Haynesville project area. The color of the cross-sections represents density-porosity. Vertical exaggeration is 10x. 5 
Figure 6 - Correction of position log pointsets with incorrect landing zone classifications. Vertical exaggeration is $10 x$. 6

Figure 7 - Fault identification in Haynesville. Vertical exaggeration is 10x. 6

Figure 8 - Fault identification in Barnett Shale using a horizontal well position log trend surface. Vertical exaggeration is $10 x .7$

Figure 9 - The comparison of horizontal well landing zones from corrected horizons to original horizons. Vertical exaggeration is $10 x . \quad 8$

Figure 10 - Cross-section from sealed faulted framework 3D geocellular model showing horizontal producers completed in the Barnett Shale formation. Vertical exaggeration is 10x.

Figure 11 - Calculation and classification of stratigraphic landing zones for well position logs. Vertical exaggeration is $10 x . \quad 9$

Figure $12-11$

Figure 13 - Buda limestone stratigraphic horizon (purple) viewed in 3D from the southwest. Figure 13a shows the horizon mapped using 350 well tops obtained using regional well log correlation. Figure 13b shows the horizon mapped conformable to the well position log trend surface for 19,000 Eagle Ford horizontal producers. Figure $13 c$ adds the horizontal well position logs for the Eagle Ford producers in white. Note that the Stuart City reef margin and Karnes Trough structures are clearly highlighted by the horizon mapped conformable to the well position log trend surface. Vertical exaggeration is 10x. 13

Figure 14 -Cross-section showing a comparison of the Eagle Ford zone mapped using 350 well tops (red) versus the Eagle Ford zone mapped conformable to the well position log trend surface (green). In this crosssection, the Eagle Ford is approximately 160 feet thick. Note the difference of 540 foot between the red and green Eagle Ford modeled zones. Vertical exaggeration is 10x. 13

Figure 15 - 3D geocellular model cross-section for the Fayetteville Shale showing density distributed in layers based on a horizontal well position log trend-corrected stratigraphic framework. Vertical exaggeration is $10 \mathrm{x} .14$

Figure 16 - Horizontal producers in the Fort Worth basin Barnett Shale showing directional survey positional error cones. Cross-sections showing both 3D geomodel porosity and geological formations are shown in the background. The grey horizon is the basement surface of the Fort Worth basin. Vertical exaggeration is $1 \mathrm{x} . \quad 16$

Figure 17 - Difference in stratigraphic framework construction between well tops from $>8,000$ wells vs 885. Note how the horizontal well trajectories (purple) are better captured using the stratigraphic correlations generated using the more densely spaced vertical wells (black lines) when compared to the original interpretation, based on 885 wells. 17

Figure 18 - North-south seismic cross section showing a comparison of the Eagle Ford stratigraphic frameworks based on 350 well tops (red) and the stratigraphic framework based on the well position log trend surface correction method (green). Vertical exaggeration is 10x. 18 